\title{
Subseasonal zonal variability of the western Pacific subtropical high in summer: climate impacts and underlying mechanisms
}

\author{
WeiNa Guan ${ }^{1} \cdot$ HaiBo Hu ${ }^{1,2}$ (D) XueJuan Ren ${ }^{1} \cdot$ Xiu-Qun Yang ${ }^{1}$
}

Received: 29 August 2018 / Accepted: 28 February 2019 / Published online: 6 March 2019

(c) The Author(s) 2019

\begin{abstract}
The zonal oscillation of the western Pacific subtropical high (WPSH) significantly influences the weather and climate over East Asia. This study investigates characteristics and mechanisms of the zonal variability of the WPSH on subseasonal time scales during summer by using a subseasonal WPSH (Sub-WPSH) index. Accompanied with the Sub-WPSH index, strong anticyclonic (cyclonic) anomalies are found over East Asia and coastal region south of $30^{\circ} \mathrm{N}$ on both $850 \mathrm{hPa}$ and $500 \mathrm{hPa}$. During the positive period of the Sub-WPSH index, the WPSH extends more westward with enhanced precipitation over the Yangtze-Huaihe river basin and suppressed precipitation over the south of the Yangtze River in China. These precipitation anomalies can last for at least 1 week. While the subseasonal zonal variability of the WPSH is found to be closely associated with atmospheric teleconnections and local air- sea interaction, the mechanisms of the variability are different before and after mid-July (early and late summer). In both early and late summer, the East Asia/Pacific (EAP) wave train pattern affects the zonal shift of the WPSH by inducing a low-level anomalous anticyclonic/cyclonic circulation over the subtropical western Pacific, and this mechanism is stronger in late summer. In constrast, the influence of the Silk-Road pattern wave train is more important in the early summer. Meanwhile, in late summer, a stronger SST forcing on the atmosphere and a faster cycle of subseasonal variations of the WPSH are observed before the westward stretch of the WPSH, which could be related to the colder local SST anomalies. The westward stretch of the WPSH is accompanied by stronger anticyclonic anomalies in late summer.
\end{abstract}

Keywords Summer Yangtze rainfall · The western Pacific subtropical high $\cdot$ Subseasonal variability $\cdot$ Rossby wave train . Local air-sea interaction

\section{Introduction}

The western Pacific subtropical high (WPSH) is a basinscale anticyclone circulation system over the West Pacific in boreal summer (Tao and Chen 1987). The WPSH is stronger and more stable in the lower- and mid-troposphere, and its variabilities are usually depicted by the $500 \mathrm{hPa}$ or $850 \mathrm{hPa}$ geopotential height fields (Tao and Zhu 1964). The

HaiBo Hu

huhaibo@nju.edu.cn

1 CMA-NJU Joint Laboratory for Climate Prediction Studies, Instituted for Climate and Global Change Research, School of Atmospheric Science, Nanjing University, Nanjing 210093, China

2 Key Laboratory of Meteorological Disaster of Ministry of Education, Nanjing University of Information Science and Technology, Nanjing 210044, China low-level southwesterly jet at the northwestern edge of the WPSH transports a large amount of water vapor into East Asia (Lu 2001; Zhou and Yu 2005). Furthermore, the shape and intensity of the WPSH dominate the position of the Meiyu front in eastern China in summer, which is located between the monsoonal warm air and cold air from middle or high latitudes (Tao and Chen 1987; Chang et al. 2000a; Zhou and Yu 2005; Zhou et al. 2009; Mao et al. 2010; Lee et al. 2013). Thus, the WPSH could strongly influence the weather and climate in East Asia during summer (Ding and Chan 2005; Lu and Dong 2001; Zhou and Yu 2009; Yang et al. 2013; Wu and Wang 2015). The WPSH demonstrates remarkable seasonal variations. The northward advance of the WPSH is closely associated with the seasonal march of the monsoon rainfall zone in eastern China (Tao and Chen 1987; Ding and Chan 2005; Yang et al. 2013). On the other hand, the WPSH also exhibits both meridional and zonal changes on interannual to decadal time scales, which are 
closely related to the low-frequency variations of the East Asian summer rainfall (Lu 2001; Lu and Dong 2001; Zhou and $\mathrm{Yu}$ 2009; Li et al. 2017).

On subseasonal time scales, pronounced variability of the subtropical high is observed at the western edge of the WPSH (Huang 1963; Tao and Zhu 1964; Kawatani et al. 2008), which significantly influences the location and intensity of the persistent heavy rainfall (PHR) events over eastern China by affecting low-level moisture transport (Wang et al. 2000b; Mao and Xu 2006; Liu et al. 2008; Mao et al. 2010). When the WPSH stretches to the westernmost position, an anomalous anticyclone appears in the lower troposphere over East Asia and favors anomalous northward moisture transport from ocean to land. The warm and moist air from the tropics converges with the cool air over eastern China, providing preferable conditions for the PHR (Tao and Chen 1987; Mao et al. 2010). It has been previously shown that the PHR events in eastern China are accompanied with the zonal variability of the WPSH. For example, the 20-50-day variability of summer Yangtze rainfall is associated with the abrupt westward (eastward) shift of the WPSH (Mao et al. 2010). Furthermore, both of the two leading intraseasonal variability modes (i.e., the biweekly and 21-30-day modes) of the Yangtze River basin summer rainfall are found to be associated with the zonal variability of the WPSH (Yang et al. 2013). By focusing on the variability of precipitation, these studies clearly suggest that the persistent precipitation anomalies over East Asia are closely associated with the subseasonal zonal variability of the WPSH. Several questions then arise regarding the subseasonal variability of the WPSH. What are the main characteristics of the subseasonal WPSH variability? What are the main areas in East Asia where precipitation anomalies are significantly affected by the WPSH on the subseasonal time scales? What are implications of the WPSH for the regional subseasonal precipitation forecasts? These questions will be addressed in this study.

The variability of the summer WPSH can be affected by air-sea interaction (Ren et al. 2013; Qian and Shi 2017) and Rossby wave trains (Chen and Zhai 2015; Enomoto et al. 2003; Yang et al. 2013). Such wave trains include the East Asia/Pacific (EAP) teleconnection pattern in the meridional direction (Huang and Li 1987; Nitta 1987) in the middle troposphere, and the Silk-Road pattern (SRP) in the zonal direction (Lu et al. 2002, Hsu and Lin 2007) in the upper troposphere. During boreal summer, the EAP pattern, also referred to as the PJ (Pacific-Japan) teleconnection, has been recognized as one of the profound teleconnection patterns over the East Asia (Huang and Li 1987; Nitta 1987; Huang 1990), and establishes a close linkage among the WPSH, the Mei-Yu front, and the Okhotsk high over Northeast Asia (Bueh et al. 2008). It has been shown that the EAP pattern has significant impacts on summer rainfall over East Asia
(Huang 1990; Lau and Weng 2002; Chen and Zhou 2014; Qian et al. 2014; Wu and Zhou 2016; Wu et al. 2016; Chen et al. 2017), and the strength of the East Asian summer monsoon (Nitta 1987; Huang 2004; Huang and Sun 1992). The EAP pattern also exhibits strong subseasonal variability ( $\mathrm{Li}$ et al. 2014; Wang and Zhang 2015; Wu et al. 2013). Wu et al. (2013) pointed out that the EAP index exhibits a statistically significant period of about $25-60$ days. In addition, Wang and Zhang (2015) revealed that the EAP pattern has an evident peak on the biweekly time scales. On the other hand, the SRP is characterized by a teleconnection pattern trapped by the Asian upper-tropospheric westerly jet in summer (Lu et al. 2002). Some studies have shown that the SRP exhibits significant variability on subseasonal time scales (Ding and Wang 2007; Enomoto et al. 2003, Hsu and Lin 2007). Tao and Wei (2006) pointed out that the SRP forms a ridge (trough) along the east coast of China, and then leads to the northwestward advancement (southeastward retreat) of the WPSH. Furthermore, Yang et al. (2013) noted that the eastward propagation of the SRP in the upper-level westerly jet could be the origin of the biweekly variations over East Asia in early summer. Considering these two prevailing Rossby wave trains over the Western Pacific region, in this study we are particularly interested in whether these wave trains have impacts on the zonal subseasonal variability of the WPSH.

On the subseasonal time scale, local air-sea interaction is also non-negligible for the generation and propagation of atmospheric subseasonal variation in middle and low latitudes. Many previous studies have studied the subseasonal air-sea interaction over the tropical Indo-Western Pacific (Wu et al. 2008a, b; Hedon and Glick 1997), the South China Sea (Wu 2010; Roxy and Tanimoto 2012; Vecchi and Harrison 2002), and the Koroshio Extension region (Wang et al. 2012) during boreal summer. However, the relationship between the WPSH and sea surface temperatures (SST) on the subseasonal time scale is still unclear. Ren et al. (2013) suggested that the positive SST anomalies (SSTAs) over the coastal region of East Asia play an important role on the eastward retreat of the WPSH on subseasonal time scales. In addition, Qian and Shi (2017) indicated that SSTAs over the tropical Indian Ocean and the tropical western Pacific are crucial for the subseasonal zonal variability of the WPSH. These studies indicated that the local SSTAs, which could be responses to the atmospheric forcing associated with the later stage of zonal variability of the WPSH, are responsible for the eastward retreat of the WPSH. However, fewer attention has been paid on the effects of local SSTAs on atmosphere during the early stage of the WPSH.

To better understand the persistent precipitation anomalies over East Asia during summer, this study attempts to investigate the basic features and mechanisms of the zonal variability of the WPSH on subseasonal time scales. The 
following questions will also to be addressed in this study: what are the differences between high and low levels of wave trains associated with the subseasonal zonal variability of the WPSH? How does the air-sea interaction modulate the intensity and period of the WPSH?

Section 2 introduces the data, the definition of the subseasonal WPSH zonal index, and statistical analysis methods used in this study. Section 3 investigates basic features of subseasonal zonal variability of the WPSH, and its connection with precipitation over East Asia and SSTAs on subseasonal time scale. The role of wave trains on the WPSH variability in early and late summer are examined in Sect. 4. Section 5 discusses the difference between air-sea interaction in early and late summer. A summary and discussions are given in Sect. 6.

\section{Data and method}

\subsection{Data}

The daily precipitation data over land (1979-2007) is used in this study from the Asian Precipitation-Highly Resolved Observation Data Integration Towards Evaluation of Water Resources (APHRODITE), which is conducted by the Research Institute for Humanity and Nature (RIHN) and the Meteorological Research Institute (MRI) of the Japan Meteorological Agency (JMA) (Xie et al. 2007; Yatagai et al. 2012). The dataset is created primarily from a rain gauge observation network. The APHRO_V1101 dataset used in this study covers the area of $15^{\circ} \mathrm{S}-55^{\circ} \mathrm{N}, 60^{\circ}-150^{\circ} \mathrm{E}$ with a high-resolution of $0.5^{\circ} \times 0.5^{\circ}$. Another daily precipitation data over land on $1^{\circ} \times 1^{\circ}$ grid from the Global Precipitation Climatology Project is used (GPCP; Huffman et al. 2001), which combines both ground and satellite observations, and spans the period of 2008-2015 as an extension of the APHRO_V1101 dataset. Besides, daily mean outgoing longwave radiation (OLR) with a spatial resolution of $1^{\circ} \times 1^{\circ}$ from the National Oceanic and Atmospheric Administration (NOAA) is used as a proxy for daily rainfall over tropical oceans and land (Liebmann and Smith 1996). The primary datasets for daily atmospheric circulation are obtained from two reanalyses for the period 1979-2015: (1) the National Centers for Environmental Prediction/National Center for Atmospheric Research (NCEP/NCAR) reanalysis products (Kalnay et al. 1996); (2) the global European Centre for Medium-Range Weather Forecasts (ECMWF) interim reanalysis (ERA-Interim; Dee et al. 2011). There are no significant differences in the atmospheric circulation results obtained from these two datasets. Thus, only results from the ERA-Interim are shown in this study. The SST dataset used in this study is extracted from the ERA-Interim for the same (a) $500 \mathrm{hPa}$ Geopotential Height

STD

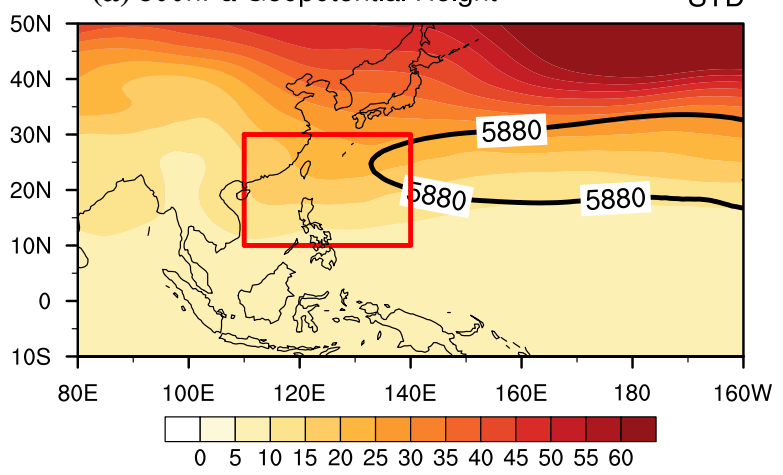

(b)

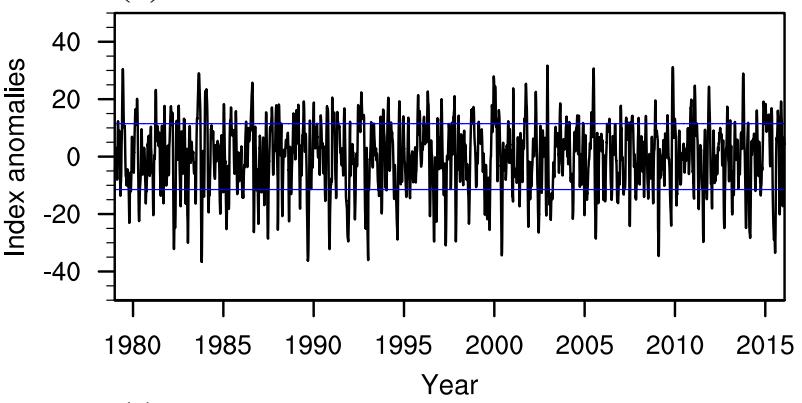

(c)

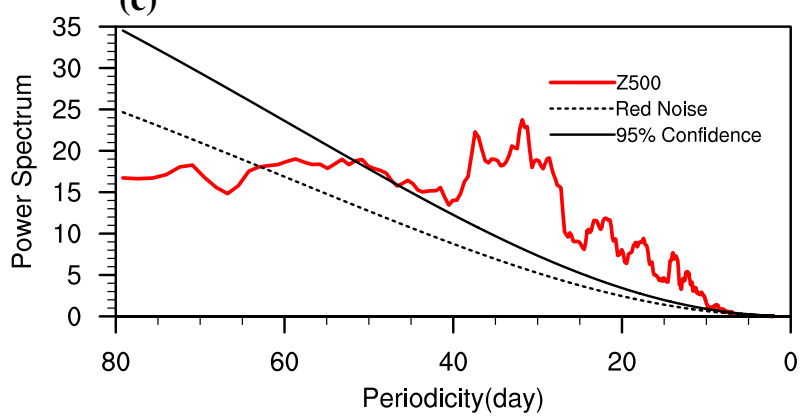

Fig. 1 a Contour represents the climatological value of $500 \mathrm{hPa}$ geopotential height (Z500) at $5880 \mathrm{~m}$ and shading denotes the standard deviation of subseasonal Z500 anomaly during the boreal summer (June-August) from 1979 to 2015. Red solid box indicates the key domain $\left(10-30^{\circ} \mathrm{N}, 110-140^{\circ} \mathrm{E}\right)$. b Time series of the Sub-WPSH index during the boreal summer (black solid line). c Power spectrum of the summer Sub-WPSH index, with Markov red noise spectrum (black dashed line), a priori 95\% confidence bound (black solid line)

period with a spatial resolution of $0.75^{\circ} \times 0.75^{\circ}$. This study focuses on the boreal summer season from June to August.

\subsection{Methods}

The subseasonal variations of the summer WPSH are measured by geopotential height anomalies at $500 \mathrm{hPa}$ (Z500). The subseasonal variability signals are obtained from the unfiltered daily time series by firstly taking a 5-day running mean after removal of the daily climatology, and then subtracting the corresponding summer mean in each year to remove the interannual signals (Krishnamurthy and Shukla 
2000; Ren et al. 2015). Figure 1a shows the standard deviation of subseasonal Z500 anomalies during summer from 1979 to 2015 . A local maximum Z500 variability center is noted over the domain $\left(10-30^{\circ} \mathrm{N}, 110-140^{\circ} \mathrm{E}\right)$, which is defined as the core region in this study. A subseasonal zonal variability index of the WPSH (hereafter the SubWPSH index) is then defined by the subseasonal JJA Z500 anomalies averaged over this core region. Note that this core region for the subseasonal Z500 variability is largely the same as that for the interannual variability of the WPSH index proposed in previous studies ( $\mathrm{Lu} \mathrm{2001;} \mathrm{Wu} \mathrm{et} \mathrm{al.}$ 2008a, b). A positive Sub-WPSH index represents the subseasonal westward extension of the WPSH, while the eastward retreat of the Sub-WPSH is represented by a negative index. Figure $1 \mathrm{~b}$ displays the time series of the daily SubWPSH index for the summers during 1979-2015. A period of 10-40 days in the Sub-WPSH index is clearly illustrated by the power-spectral analysis (Fig. 1c). A positive (negative) case is identified when the Sub-WPSH index exceeds positive (negative) one standard deviation and persists for at least 3 days. According to this criteria, 51 positive cases and 59 negative cases are identified during the summers of 1979-2015. The lead-lag composites can then be conducted for the selected positive and negative events. The day corresponding to the maximum (minimum) in the Sub-WPSH index for each positive (negative) case is defined as day 0 . Each negative (positive) lag day indicates the particular day leads (lags) day 0.

Since climatologically a northward jump of the WPSH occurs in mid-July, very different characteristics in summer rainfall has been suggested over East Asia before and after mid-July due to remarkable differences in the state of mean circulation (Tao and Chen 1987; Lu 2001; Ding and Chan 2005). Thus, in the following analysis we further divide the whole summer into two periods (early summer from June 1 to July 15 and late summer from July 16 to August 31).

A daily EAP index is defined by Z500 anomalies over three locations, namely, the subtropical western Pacific, midlatitudes of East Asia, and Okhotsk Sea, following previous studies (Eq. 1, Nitta 1987; Kosaka and Nakamura 2006; Bueh et al. 2008; Hirota and Takahashi 2012). Similarly, the SRP index is defined using daily Z200 anomalies over three other representative activity centers (Eq. 2, Wakabayashi and Kawamura 2004)

$$
\begin{aligned}
\text { EAPI }= & 1 / 3 Z 500\left(20^{\circ} \mathrm{N}, 120^{\circ} \mathrm{E}\right)-1 / 3 Z 500 \\
& \left(37.5^{\circ} \mathrm{N}, 120^{\circ} \mathrm{E}\right)+1 / 3 \mathrm{Z} 500\left(60^{\circ} \mathrm{N}, 130^{\circ} \mathrm{E}\right)
\end{aligned}
$$

SRPI $=1 / 3 Z 200\left(65^{\circ} \mathrm{E}, 40^{\circ} N\right)-1 / 3 Z 200$

$$
\left(100^{\circ} \mathrm{E}, 40^{\circ} \mathrm{N}\right)+1 / 3 \mathrm{Z} 200\left(130^{\circ} \mathrm{E}, 40^{\circ} \mathrm{N}\right)
$$

\section{Characteristics of the zonal variability of the Sub-WPSH}

Figure 2 illustrates composite patterns of lower-tropospheric circulation, SST, and precipitation anomalies based on 51 positive and 59 negative cases at day 0 . When the SubWPSH index is positive, the wind anomalies at $850 \mathrm{hPa}$ are characterized by a strong anomalous anticyclonic circulation over the core region $\left(10-30^{\circ} \mathrm{N}, 110-140^{\circ} \mathrm{E}\right)$ and a relatively weak cyclonic circulation to the northeast of the core region (Fig. 2a). The anomalous anticyclone at $850 \mathrm{hPa}$ and positive $\mathrm{Z} 500$ anomalies over the core region indicate the westward extension of the WPSH (Fig. 2a). The western edge of the WPSH, represented by the western part of the 5880-gpm isoclines at $500 \mathrm{hPa}$ geopotential height field (hereafter $5880-$ line), extends westward to $115^{\circ} \mathrm{E}$. The anomalous anticyclone in the lower and middle troposphere over the core region favors northward moisture transport to the Yangtze-Huaihe river basin. At the same time, the anomalous cyclone to the north of the core region enhances southward transport of cold air. These anticyclone and cyclone circulation anomalies at $850 \mathrm{hPa}$ together lead to low-level convergence and above-normal precipitation over the Yangtze-Huaihe river basin. Meanwhile, below-normal precipitation is seen over the south of the Yangtze River (Fig. 2e). These precipitation anomalies can last for at least a week. Note that this anomalous precipitation pattern associated with the subseasonal WPSH variability is quite different from the distribution of subseasonal precipitation anomalies over East Asia as described in Mao et al., (2010). For example, two precipitation patterns are identified by Mao et al. (2010), with the first empirical orthogonal function (EOF) mode characterized by a dipole-like precipitation pattern over eastern china and the second EOF mode dominated by coherent rainfall variations throughout the entire Yangtze Basin. Therefore, the anomalous rainfall pattern associated with the Sub-WPSH shown in Fig. 2 may reflect a combined pattern of those corresponding to the two EOF modes, which will be further discussed in Sect. 4.1. The patterns of Z500 and precipitation anomalies for negative cases (Fig. 2b) largely mirror those for positive cases with opposite signs.

Accompanied by the westward extension of the SubWPSH, positive SSTA are evident over the western edge of the WPSH for positive Sub-WPSH index cases (Fig. 2c), while negative SSTAs are observed for the negative cases (Fig. 2d). The simultaneous composites of subseasonal OLR anomalies for positive cases show that convection is slightly enhanced over the north of $30^{\circ} \mathrm{N}$ and strongly suppressed south of $30^{\circ} \mathrm{N}$ (Fig. 2e). The spatial distribution of OLR anomalies for negative cases is approximately reversed to those for positive ones. 
(a) Z500\&wind850

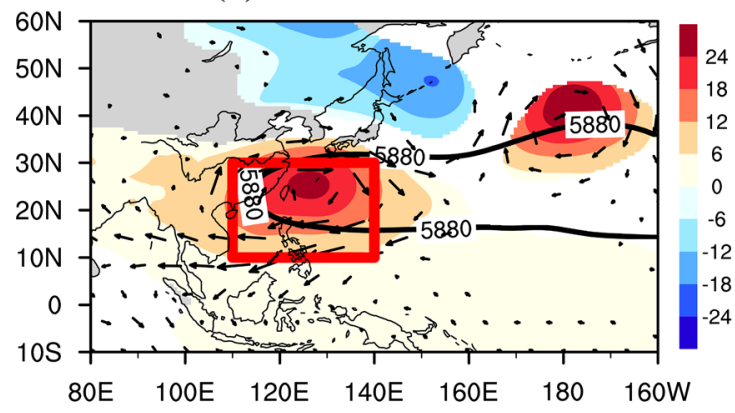

(c) SST anomaly

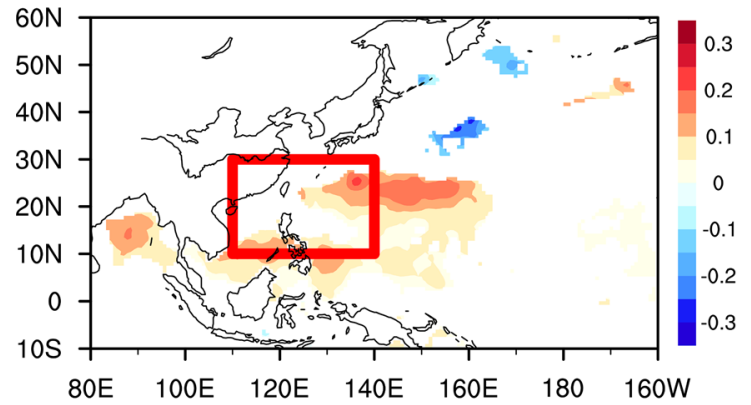

(e) rain anomaly

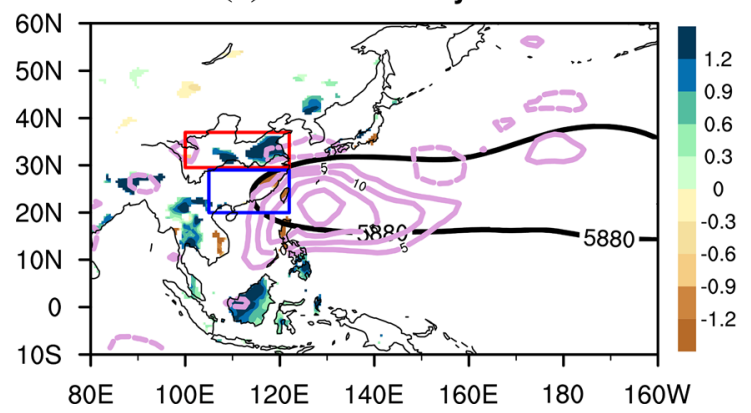

Fig. 2 Simultaneous composites of the geopotential height anomaly (shaded) at $500 \mathrm{hPa}$, wind anomaly (vector) at $850 \mathrm{hPa}$, SST anomaly (shaded) and precipitation anomaly (shaded) for the composite positive cases $(\mathbf{a}, \mathbf{c}, \mathbf{e})$ and negative cases $(\mathbf{b}, \mathbf{d}, \mathbf{f})$. The black lines are 5880-m geopotential height contour, and the purple contour shows

The WPSH is usually respresented by the 5880 geopotential meter $(\mathrm{gpm})$ isoline at $500 \mathrm{hPa}$ or the $1490 \mathrm{gpm}$ isoline at $850 \mathrm{hPa}$ (hereafter the 5880-line and the 1490-line). Composites of the 5880 -line at $500 \mathrm{hPa}$ and the 1490 -line at $850 \mathrm{hPa}$ for the positive and negative Sub-WPSH cases at lag days from -8 to +8 are shown in Fig. 3. The zonal variability of the Sub-WPSH can be clearly seen in Fig. 3. For positive Sub-WPSH cases (Fig. 3a), the westernmost edge of the 5880 -line is located near $134^{\circ} \mathrm{E}$ at day -8 . Then, it stretches westward from day -6 and finally reaches the westernmost location at day 0 . After that, the western part of the WPSH begins to withdraw eastward (Fig. 3c). For positive SubWPSH cases the WPSH at $850 \mathrm{hPa}$ exhibits similar evolution features, namely, first westward then eastward migration as

\section{(b) Z500\&wind850}

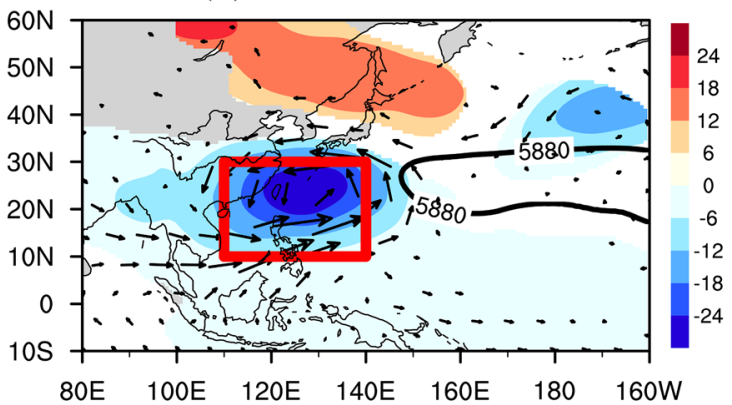

(d) SST anomaly

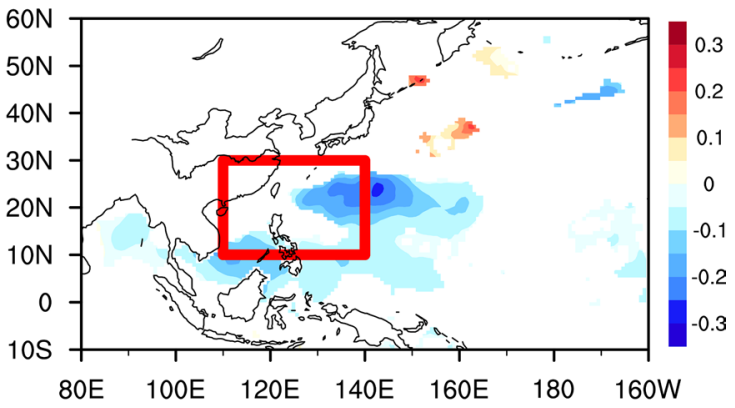

(f) rain anomaly

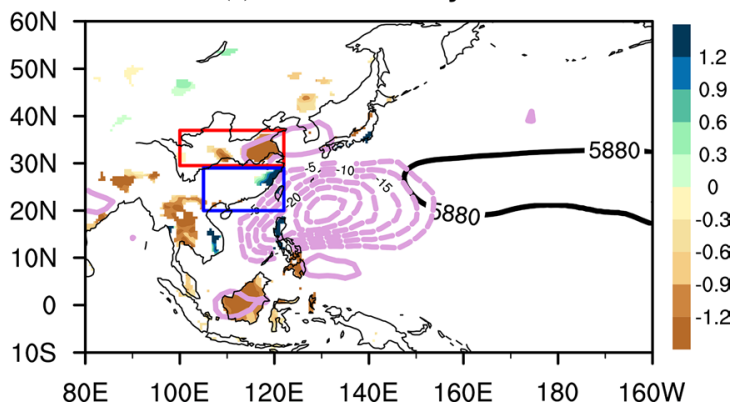

the OLR anomaly. The shading areas and vectors are significant at 95\% confidence level for all variables. Red thick solid boxes indicate the Sub-WPSH key region $\left(10-30^{\circ} \mathrm{N}, 110-140^{\circ} \mathrm{E}\right)(\mathbf{a}, \mathbf{b}, \mathbf{c}, \mathbf{d})$. Two precipitation domains are defined by the red box $\left(29-37^{\circ} \mathrm{N}, 100\right.$ $\left.122^{\circ} \mathrm{E}\right)$, and blue box $\left(20-29^{\circ} \mathrm{N}, 105-122^{\circ} \mathrm{E}\right)(\mathbf{e}, \mathbf{f})$

denoted by the 1490-line (Fig. 3e, g). However, for negative cases, both the 5880 (Fig. 3b, d) and 1490 lines (Fig. 3f, h) exhibit zonal variability with eastward movement from day -8 to 0 , and then westward movement from day 0 to 8 .

To investigate the temporal evolution characteristics related to the Sub-WPSH, the lagged composites of Z500, SST and precipitation anomalies for positive and negative Sub-WPSH index cases are plotted in Fig. 4. A positive Z500 anomalous center is seen over the eastern part of the core region at day -4 , then moves westward with increasing strength in the following days, and reaches its maximum intensity at day 0 (Fig. 4a). After that, the positive Z500 center continues moving westward, meanwhile it starts to be weakened after day 0 , and finally disappears at day +8 . 
(a) Z500 lead

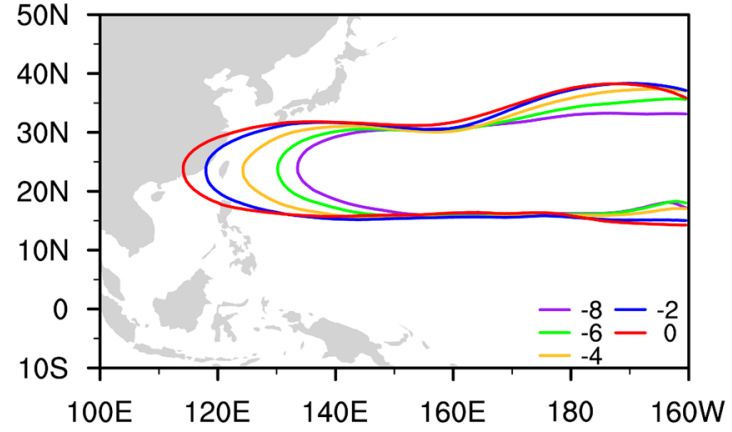

(c) Z500 lag

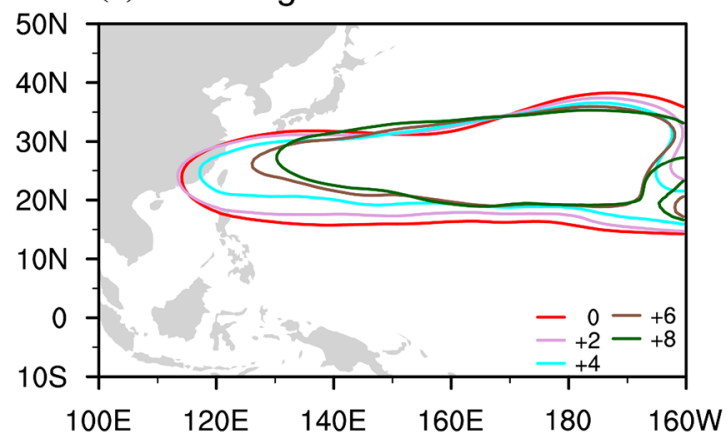

(e) Z850 lead

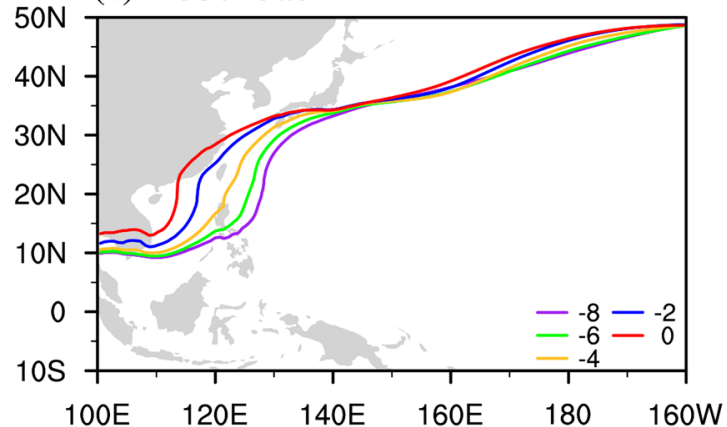

(g) Z850 lag

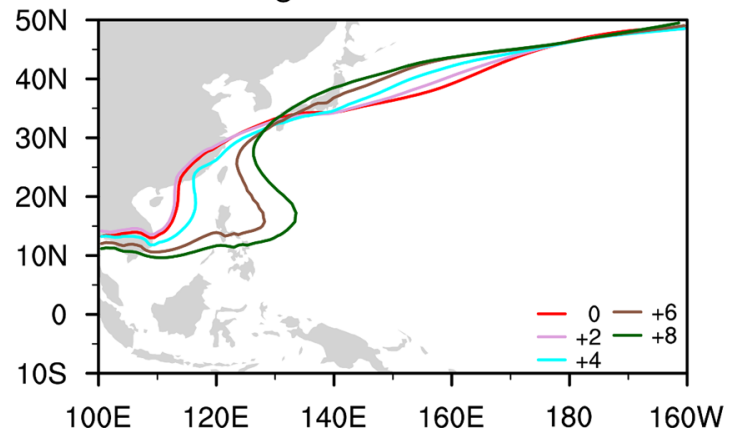

(b) Z500 lead

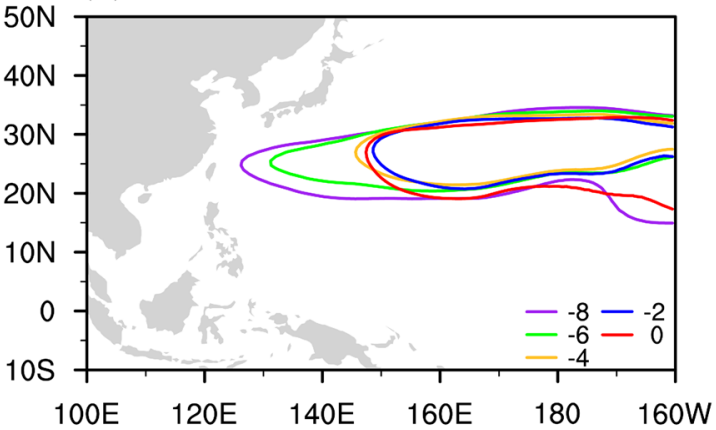

(d) Z500 lag

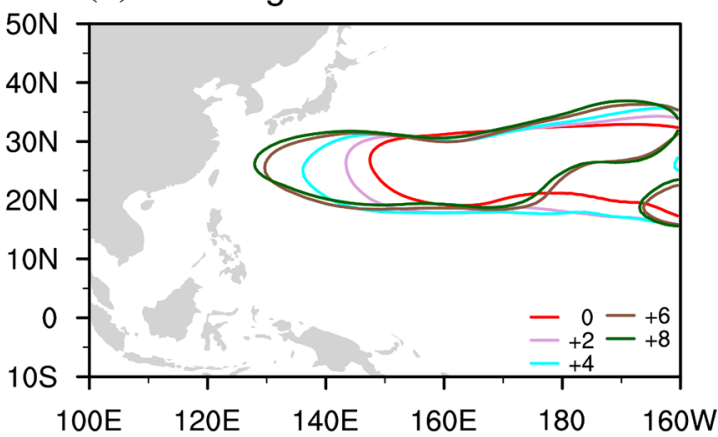

(f) Z850 lead

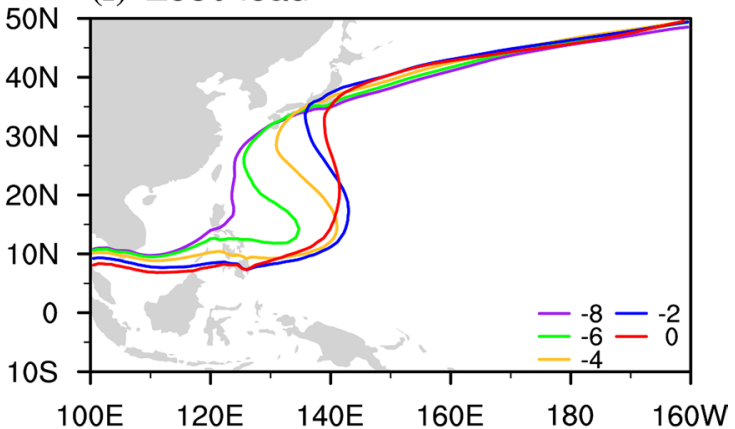

(h) Z850 lag

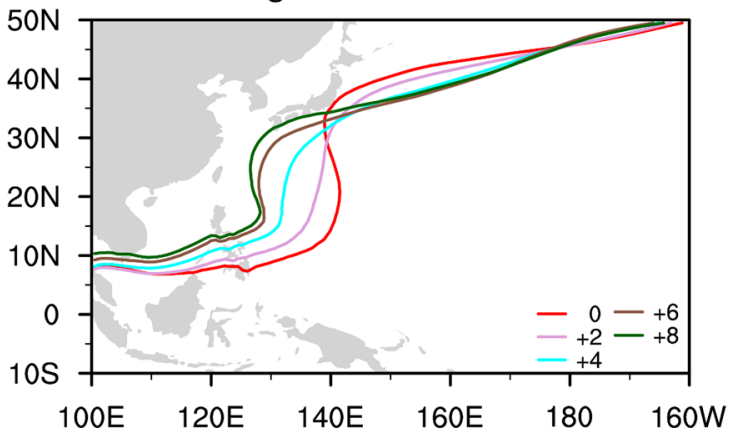

Fig. 3 Lagged composites of the 5880-line at $500 \mathrm{hPa}(\mathbf{a}-\mathbf{d})$ and 1490-line at $850 \mathrm{hPa}(\mathbf{e}-\mathbf{h})$ with positive (left) and negative Sub-WPSH cases (right). The lags show a range from -8 to +8 days with an interval of 2 days

This evolution feature in the Z500 anomalies is consistent with the zonal migration of the 5880-line as discussed in Fig. 3 associated with subseasonal movement of the WPSH, a north-south dipole pattern with opposite rainfall anomalies is discerned over the Yangtze River region (Fig. 4b). Meanwhile, negative SSTAs are evident over the core region before day 0 , then quickly change to positive values around day 0 , and gradually increase after day 0 (Fig. 4a). 
Fig. 4 a Lagged composites of the geopotential height anomaly at $500 \mathrm{hPa}$ (green contours),

SST anomaly (shaded) and the 5880-line (black contours) for positive Sub-WPSH cases. The lags show a range from -8 to +8 days with an interval of 4 days. The dots denote the areas with significant at $95 \%$ confidence level for SST. Red solid box indicates the key domain $\left(10-30^{\circ} \mathrm{N}, 110-140^{\circ} \mathrm{E}\right)$. b Lagged composites of rain anomaly (shaded) and OLR (purple contours). The shading areas are significant at $90 \%$ confidence level. Two precipitation domains are also defined as Fig. 2

positive cases

(a) Z500\&SST
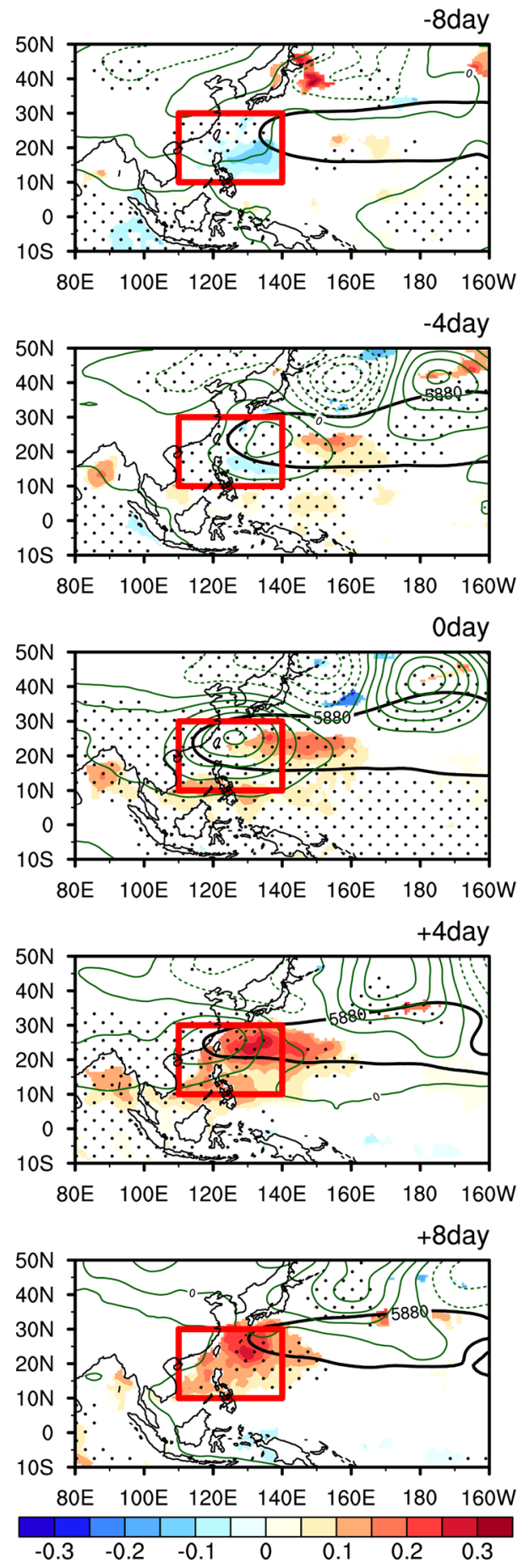

(b) rain anomaly
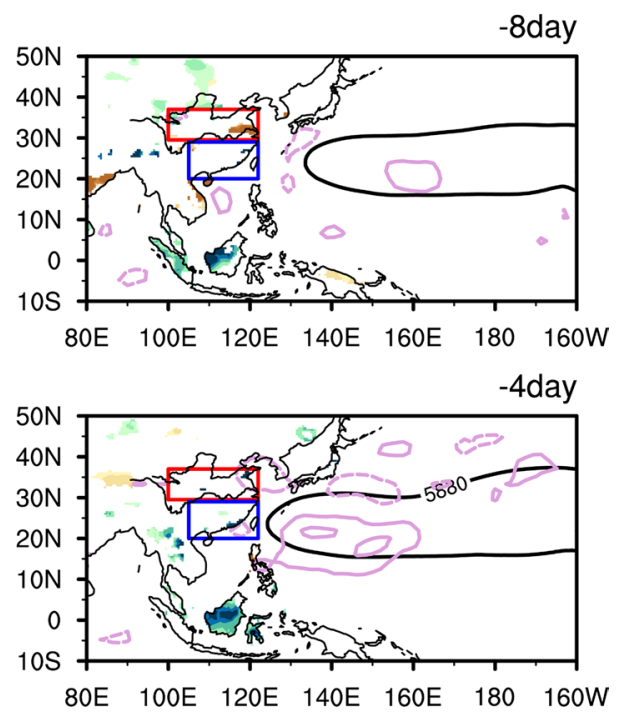

Oday
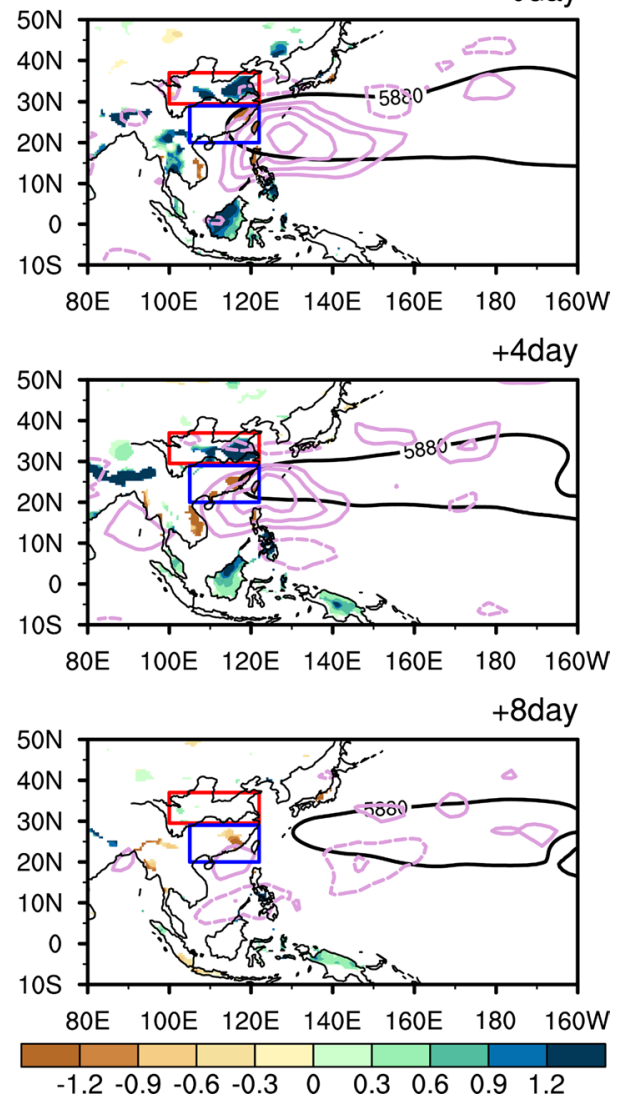

Time evolution of Z500 and SST anomalies averaged over the core region are further shown in Fig. 5 based on composites for both positive and negative Sub-WPSH cases.
In addition, a precipitation index is defined as precipitation anomalies averaged over two regions (R1: $29-37^{\circ} \mathrm{N}$, $100-122^{\circ} \mathrm{E}$, and R2: $20-29^{\circ} \mathrm{N}, 105-122^{\circ} \mathrm{E}$ ), which shows a 
largely out of phase relationship as shown in Fig. 5b. Figure 5a again shows negative SSTAs over the core region before day 0 in association with the westward extension of the Sub-WPSH, while positive SSTAs start to develop at day 0 when the maximum positive $Z 500$ anomalies are observed, implying that the positive Z500 anomalies lead positive SSTAs by several days. Additionally, the precipitation anomalies over R1 reaches the maximum at day 3, lagging the positive $\mathrm{Z} 500$ anomalies by about 3 days. Hence, the Sub-WPSH index can be a useful predictor for subseasonal precipitation prediction over East Asia. For negative Sub-WPSH cases, Fig. 5b largely shows a mirror image of positive Sub-WPSH cases.

\section{Characteristics of wave trains in early and late summers associated with the Sub-WPSH}

\subsection{Two wavetrain patterns associated with Sub-WPSH}

As mentioned in the introduction, Rossby wave trains can influence the position and intensity of the WPSH. Here, impacts of the two prevailing mid-latitude Rossby wave trains, i.e., the EAP and SRP wave trains, on the WPSH in early and late summer are examined.

Figure 6 illustrates lag-correlations of the Sub-WPSH index against the EAP and SRP indices, respectively. A positive correlation between the EAP and Sub-WPSH indices at lag day 0 is clearly seen in late summer (Fig. 6b), but no significant correlations between these two indices in early summer (Fig. 6a). However, if the high-latitude anomalous Z500 center is excluded when calculating the EAPI (i.e., defined as EAP-II I $=1 / 2 \mathrm{Z} 500\left(20^{\circ} \mathrm{N}, 120^{\circ} \mathrm{E}\right)-1 / 2 \mathrm{Z} 500\left(37.5^{\circ} \mathrm{N}, 120^{\circ} \mathrm{E}\right)$, a significant positive correlation between the EAP-II and Sub-WPSH indices is clearly seen for both early and late summer (Fig. 6d), with a slightly higher correlation in late summer than that in early summer (Fig. 6c). For lag correlations between the SRP and Sub-WPSH indices (Fig. 6e, f), a positive correlation is evident in early summer (Fig. 6e) with the maximum correlation at day 0 . However, no significant correlation is found in late summer, only a small positive correlation is found when the SRPI leads the Sub-WPSH index (Fig. 6f).

However, the EAP and SRP wave trains cannot be clearly seen in the upper and lower troposphere in composite results based on the Sub-WPSH index (figure not shown). The analyses in Sect. 3 have shown an opposite sign in precipitation anomalies between the Yangtze-Huaihe river basin and the south of the Yangtze River accompanied with the zonal variability of Sub-WPSH, which could be due to the combination of the two leading subseasonal precipitation modes as described by Mao et al. (2010). If these two modes are affected by different wave trains, composites based on subseasonal precipitation might not express the different wave trains. To further elaborate this point, a similar EOF analysis following Mao et al. (2010) is conducted for subseasonal daily rainfall data in eastern part of China for June-August during 1979-2015 to obtain the two leading modes of precipitation. Figure 7 shows the first (EOF1) and second (EOF2) mode of subseasonal rainfall variation, explaining $17.7 \%$ and $13.0 \%$ of variances, respectively. The EOF1 (Fig. 7a) exhibits a north-south dipole pattern with opposite precipitation anomalies over the south and north of the Yangtze River. In contrast, EOF2 (Fig. 7c) captures coherent rainfall variations throughout the entire Yangtze Basin. These results are consistent with Mao and Wu (2010). The dominant periods of PC1 and PC2 are both 10-40 days (Fig. 7b, d), in agreement with the primary period of the Sub-WPSH index. The relationships among the EAP, SRP indices and PC1 (PC2) can be clearly seen in their lag correlations (Fig. 8). Positive correlations can be
Fig. 5 Subseasonal time series of the region averaged subseasonal Z500 (red line), SST (blue line) over the key region $\left(10-30^{\circ} \mathrm{N}, 110-140^{\circ} \mathrm{E}\right)$ for positive Sub-WPSH cases (a) and negative cases (b). The precipitation indexes are regional averaged over R1 $\left(29-37^{\circ} \mathrm{N}\right.$, $\left.100-122^{\circ} \mathrm{E}\right)$ (orange line) and R2 (20-29 $\left.{ }^{\circ} \mathrm{N}, 105-122^{\circ} \mathrm{E}\right)$ (green line), respectively (a)

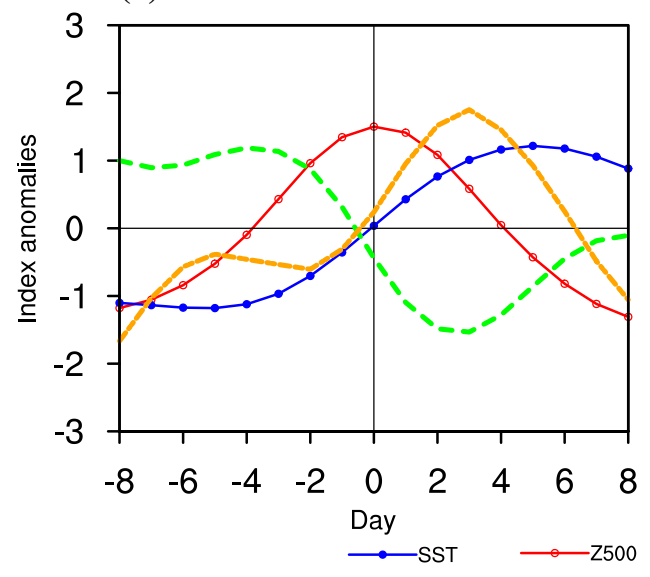

(b)

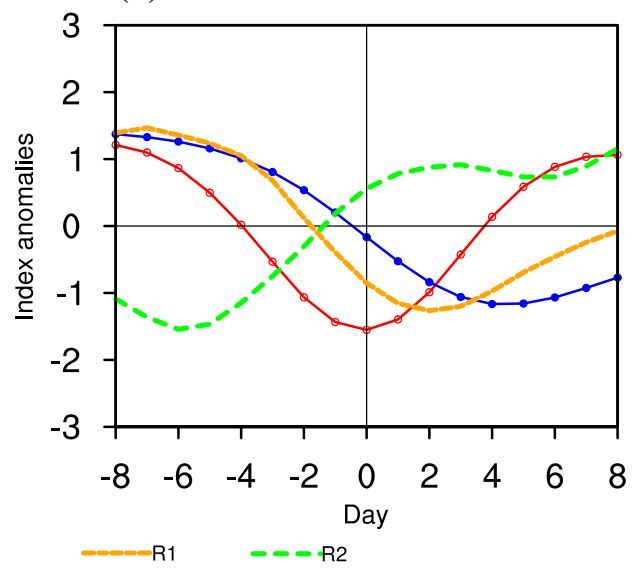


early summer

(a) EAPI-WPSHI

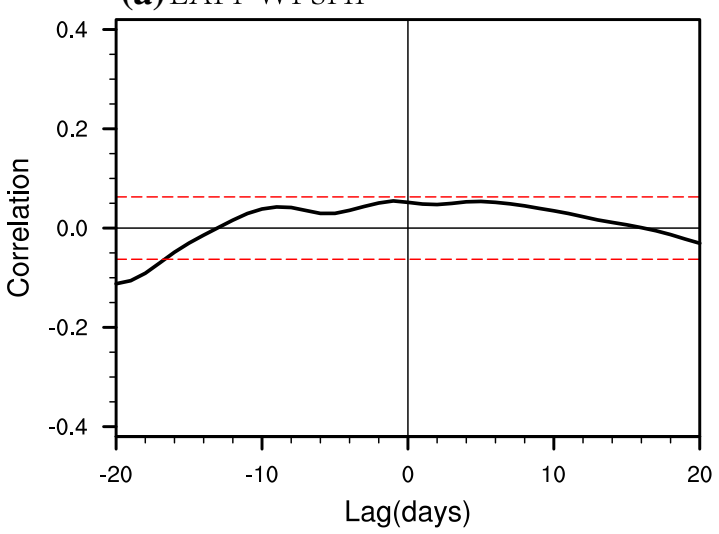

(c) EAPI-WPSHI

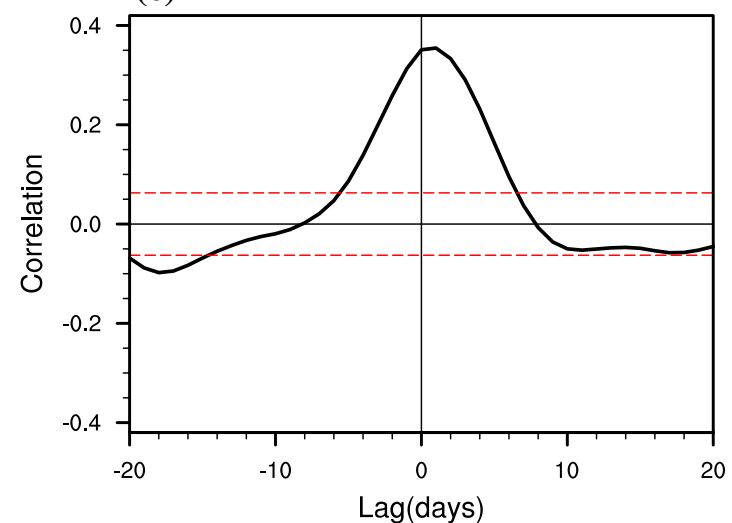

(e) SRPI-WPSHI

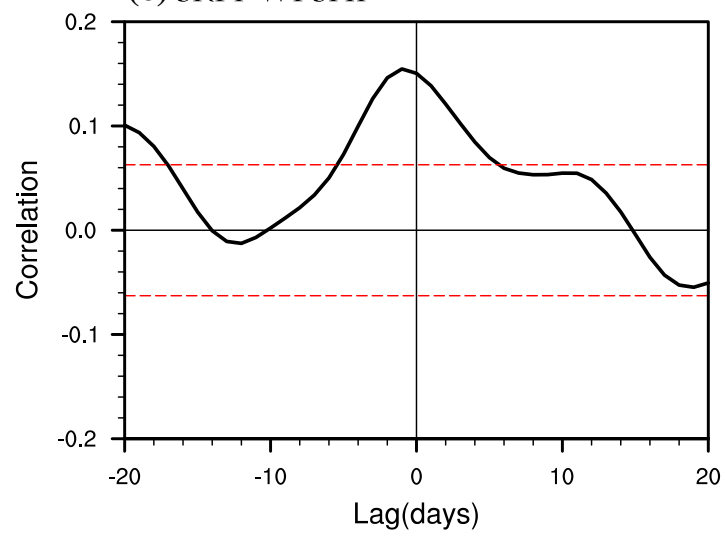

Fig. 6 Lag correlations between the Sub-WPSH and EAP indexes $(\mathbf{a}, \mathbf{b})$, Sub-WPSH and EAP-II indexes (c, d), Sub-WPSH and SRP indexes $(\mathbf{e}, \mathbf{f})$ for early summer (left) and late summer (right). Nega-

clearly seen between the EAP index and PC2 (Fig. 8c), and also between the SRP index and PC1 (Fig. 8b). Thus, the subseasonal rainfall variability over the eastern China as denoted by the EOF1 tends to be linked to the SRP, while EOF2 pattern reflects influences on the regional precipitation by the EAP. The characteristics of the two wave trains late summer

(b) EAPI-WPSHI

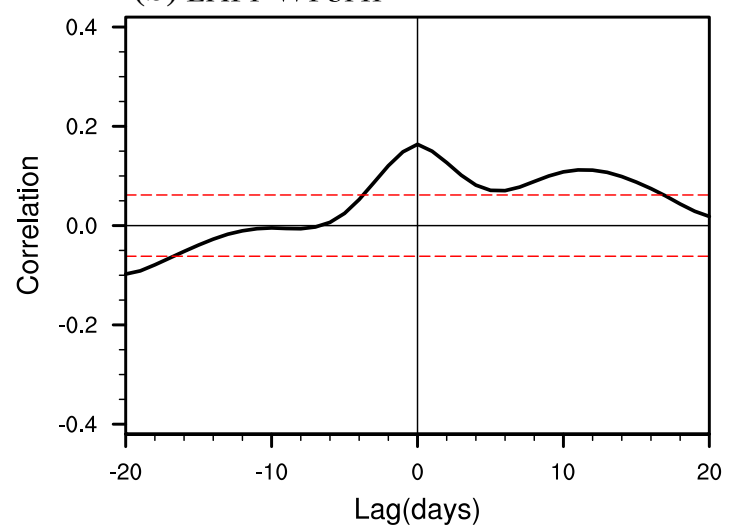

(d) EAPI-WPSHI

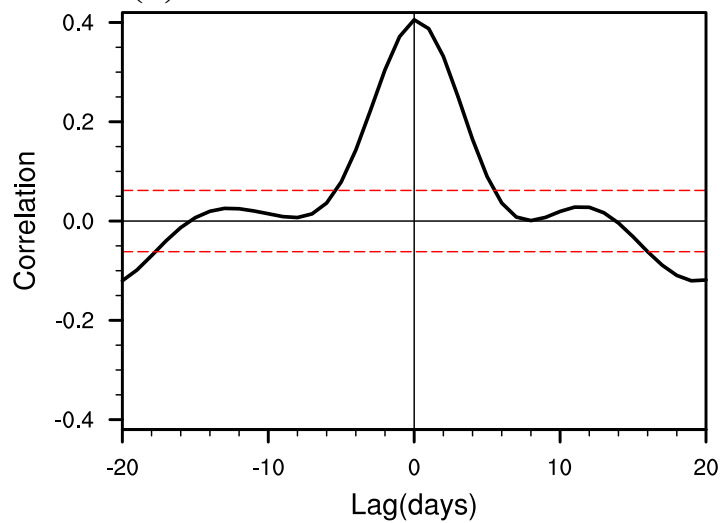

(f) SRPI-WPSHI

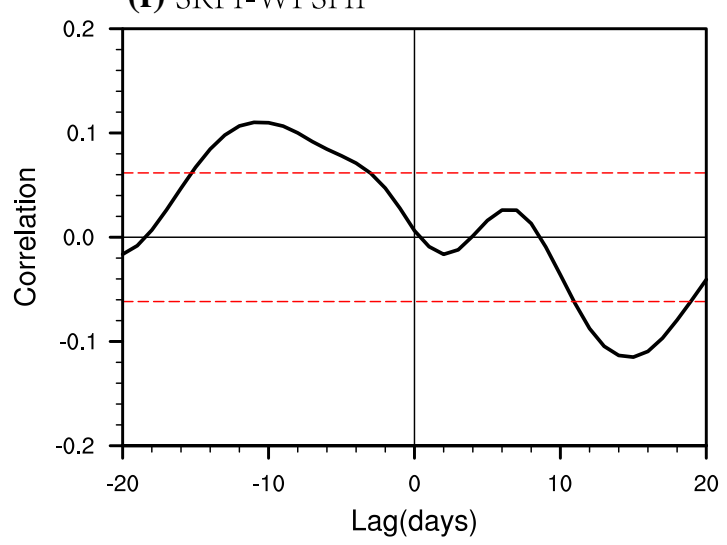

tive days indicate the wave train indexes leading Sub-WPSH index. The red lines are significant at 99\% confidence level

are further examined by composites based on cases when $\mathrm{PC} 1$ or $\mathrm{PC} 2$ exceeds $+1(-1)$ standard deviation.

\subsection{Upper troposphere wave trains with Sub-WPSH}

In order to explore the possible influences of the SRP wave train on the Sub-WPSH, positive and negative cases are 
Fig. 7 Spatial patterns of the first two leading EOFs of the subseasonal rainfall anomalies for the period June-August from 1979 to 2007 over eastern China, for a EOF1 and $\mathbf{c}$ EOF2. The percentage at the top of each panel refers to the variance explained by the mode. Power spectrum of time series of $\mathrm{PC} 1$ (b) and PC2 (d), with Markov red noise spectrum (black dashed line), a priori $95 \%$ confidence bound (black solid line) (a) EOF 1

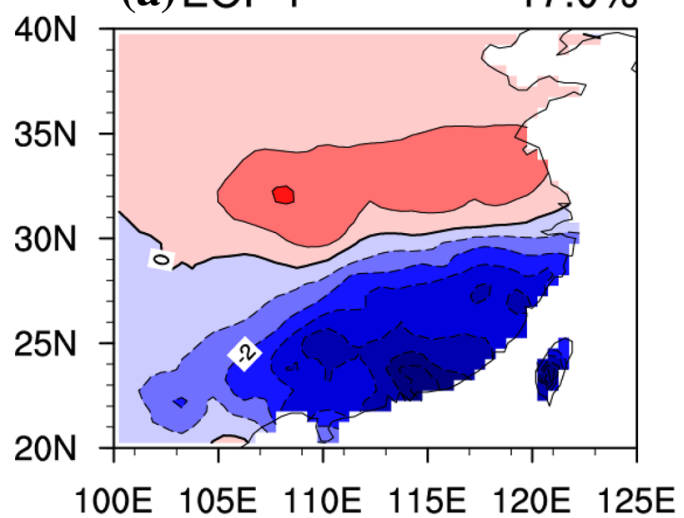

(c) EOF 2

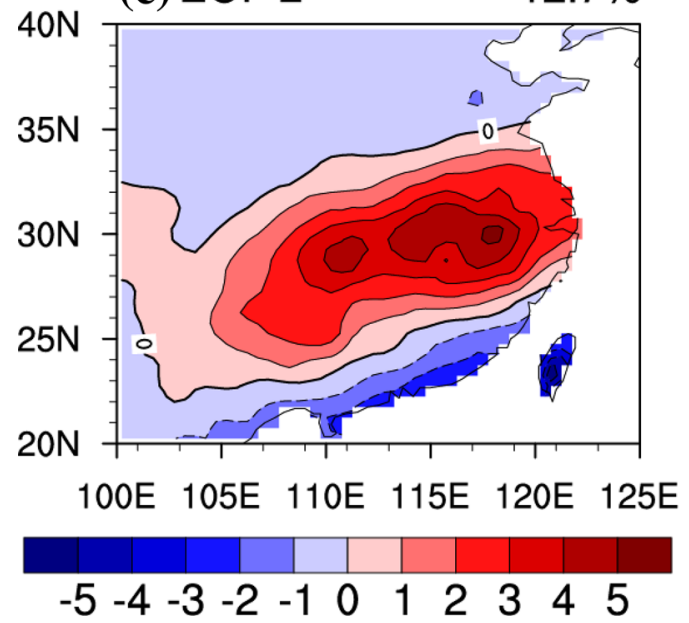

(b)
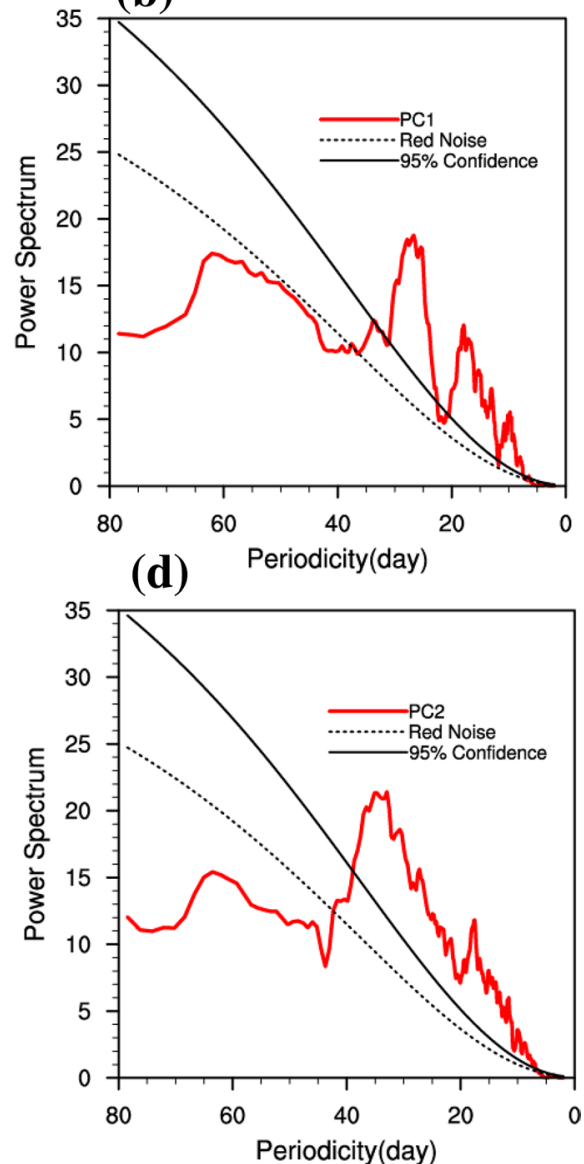

selected for composite analyses when the PC1 exceeds positive (negative) one standard deviation and persists for at least 3 days. During early summer, the "Silk Road pattern"-like Rossby wave train can be clearly seen in the upper troposphere during the evolution of the EOF1 rainfall pattern (Fig. 9a). The wave train along the Asian westerly Jet propagates eastward, starting from the Aral Sea, via northwest of Tibetan Plateau (TP), and then arrives at the north of the core region. Thus, the appearance of the upper-level anomalous anticyclonic circulation over the northern part of the core region at day 0 as shown in Fig. 4 is part of the propagating SRP wave train. From day 0 to +8 , the anticyclonic circulation finally dissipates south of Japan. In contrast, the eastward-propagating wave train in the upper troposphere cannot be clearly seen in late summer (Fig. 9b). The close association between the PC1 and the SRPI in early summer could be due to the strong jet stream which serves as a waveguide for the Rossby wave propagation (Yang et al. 2013; Terao 1998). In contrast, the wave-guide becomes weakened in late summer, therefore the SRP wave train is not clearly seen. These results indicate that the SRP plays a dominant role for subseasonal precipitation variability over East Asia in early summer. In next section, we will further show that the EAP pattern is closely linked to the rainfall EOF2 mode.

\subsection{Wave trains in the middle troposphere with the Sub-WPSH}

Now that the EOF1 of precipitation is shown to be related to the SRP wave train in early summer, a question to be addressed in this part is whether the the second mode (EOF2) is associated with the two wave trains considering the Sub-WPSH variation? A similar composite analysis is conducted based on the PC2 time series (Fig. 10). In late summer, a meridional triple structure of the EAP pattern is well established from day -4 to 0 . Especially at day 0 , two centers of positive Z500 anomalies are clearly seen, one near the sea of Okhotsk and the other near the subtropical western Pacific area, and negative Z500 anomalies are sandwiched between them (Fig. 10b). The positive Z500 anomalies associated with the EAP is evident over the core region, in accord with the westward extension of the WPSH. After day 0, the WPSH retreats eastward with decrease of the positive $\mathrm{Z} 500$ anomalies over the core region. 
(a) EAPI-PC1

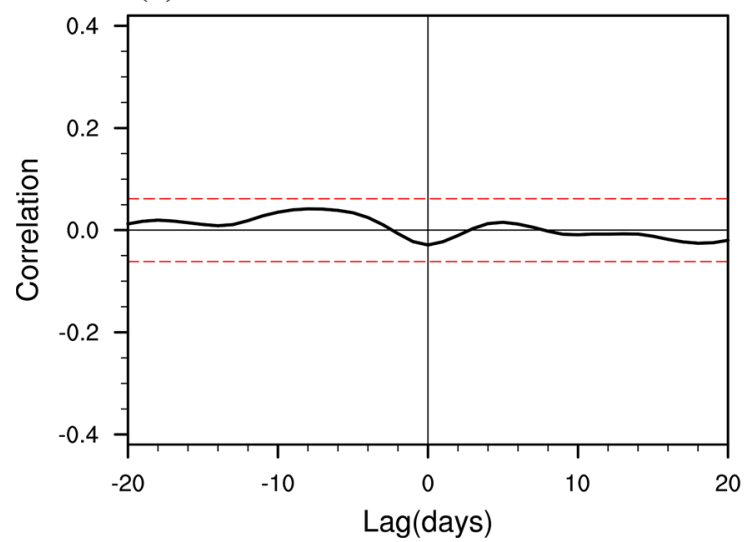

(b) SRPI-PC1

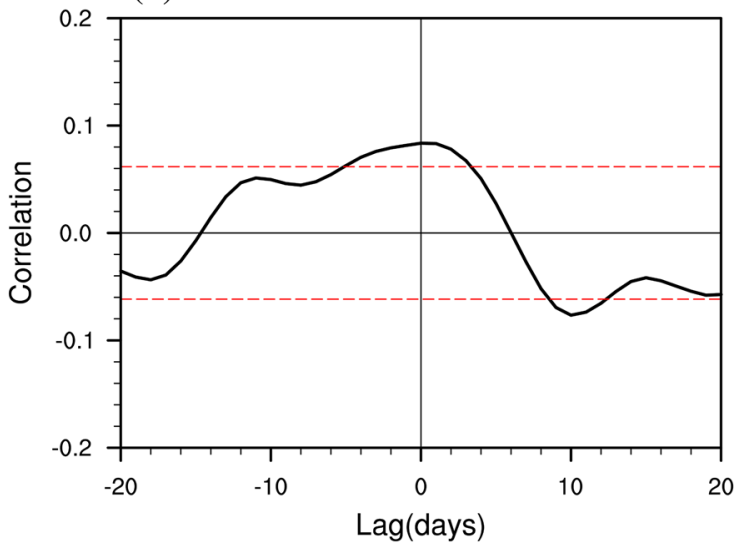

(c) EAPI-PC2

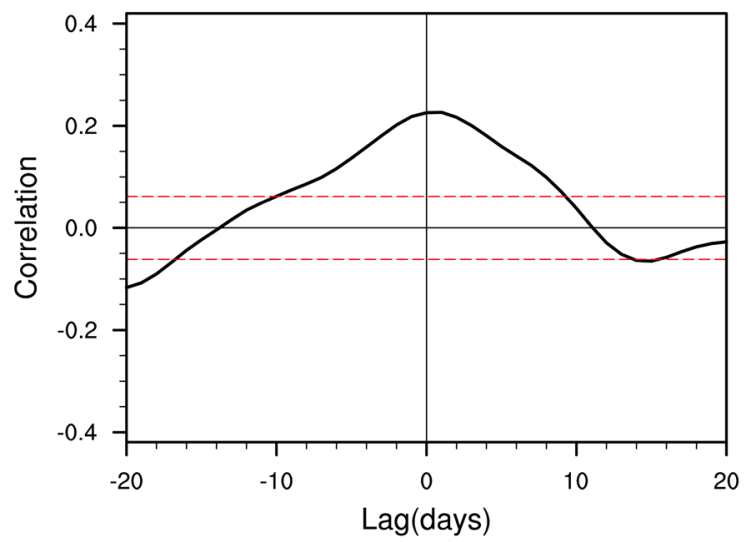

(d) SRPI-PC2

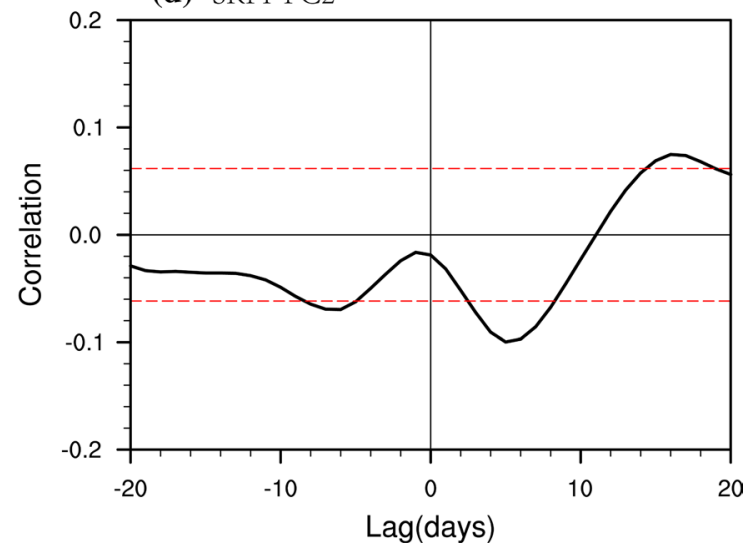

Fig. 8 Lead-lag correlations of PC1- EAPI (a), PC1-SRPI (b), PC2-EAPI (c), PC2-SRPI (d). Negative days indicate EAPI or SRPI leading precipitation PC indexes. The red lines show the significant at $99 \%$ confidence level

Similarly, there are positive Z500 anomalies over the core region and negative Z500 anomalies over north of the core region at day 0 in early summer (Fig. 10a). Compared with late summer, there are no obvious positive anomalies at high latitudes at this time. The two anomalous Z500 centers at mid-low latitudes first appear at day -8 and persist for several days. The positive Z500 anomalies over the core region switch from positive to negative values from day 0 to 8 , indicating the eastward retreat of the WPSH. Thus, it is suggested that the EAP is connected with subseasonal rainfall variability over East Asia in both early and late summer, while the SRP pattern has impacts in early summer.

\section{Local air-sea interaction during Sub-WPSH zonal variability}

\subsection{Evolution of subseasonal SSTA and Z500 anomalies}

Figure 5 shows that local air-sea interaction has an effect on the later stage of the zonal variability of the
Sub-WPSH, but is there a difference between early and late summer? To investigate this question, the lagged composites of subseasonal SSTAs are performed for the positive Sub-WPSH cases in early and late summer, respectively (Fig. 11). In both early and late summer, negative SSTAs are found over the core region during the westward extension of the WPSH, with a stronger SSTA amplitude in late summer than that in early summer. After day 0 , the warm SSTAs in late summer is stronger than that in early summer during the eastern retreat of Sub-WPSH. Figure 12 displays the composite Z500, Z850, and SST anomalies averaged over the core region in early and late summer. The negative SSTAs in the early stage of the westward extension of the WPSH (before day 0) are associated with increase of Z500 and Z850 anomalies in early summer. As a result, the $Z 500$ and $Z 850$ anomalies in early summer are stronger than that in late summer at day 0 . The larger SSTA after day 0 forms an unfavorable condition for maintaining the Z500 and Z850 anomalies in early summer, speeding up the decline of local anticyclonic anomalies. Thus, the maintenance cycle of Z500 and Z850 anomalies in late summer is shorter than that in early summer. 
Fig. 9 Lagged composites of the geopotential height anomaly at $200 \mathrm{hPa}$ (shades) for PC1 positive cases a for early summer, $\mathbf{b}$ for late summer. The lags show a range from -8 to +8 days with an interval of 4 days. The shading areas are significant at $95 \%$ confidence level for Z200 (a) Z200 in early summer
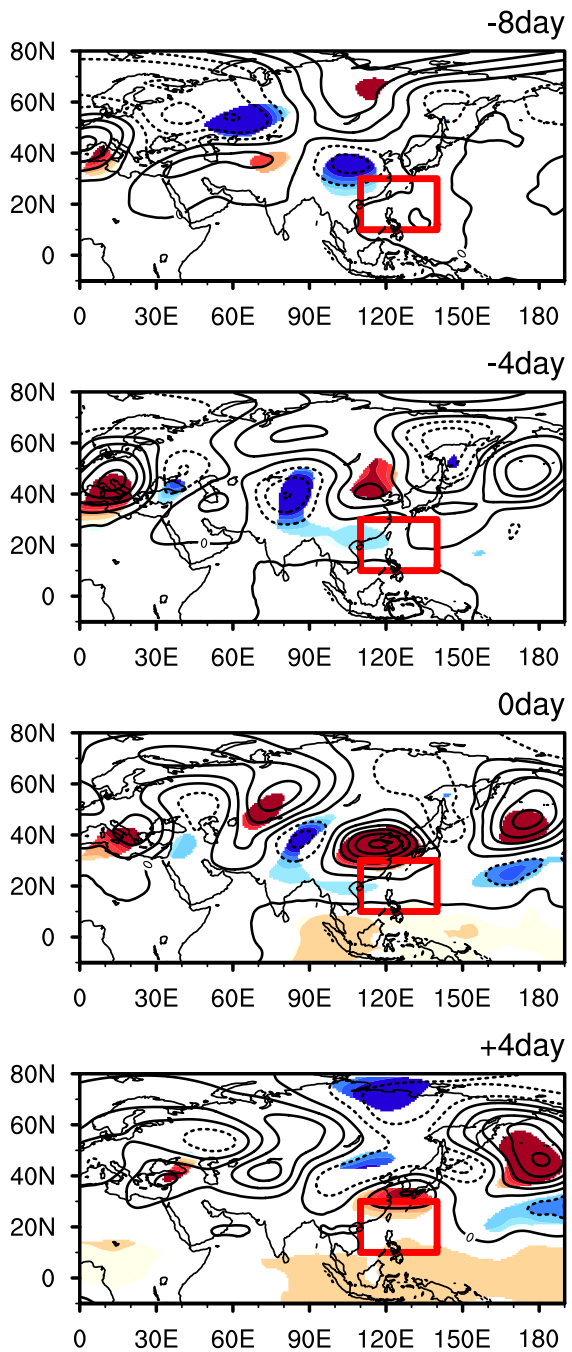

+8 day

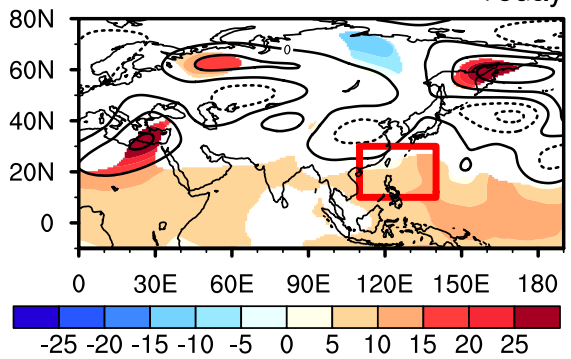

(b) Z200 in late summer
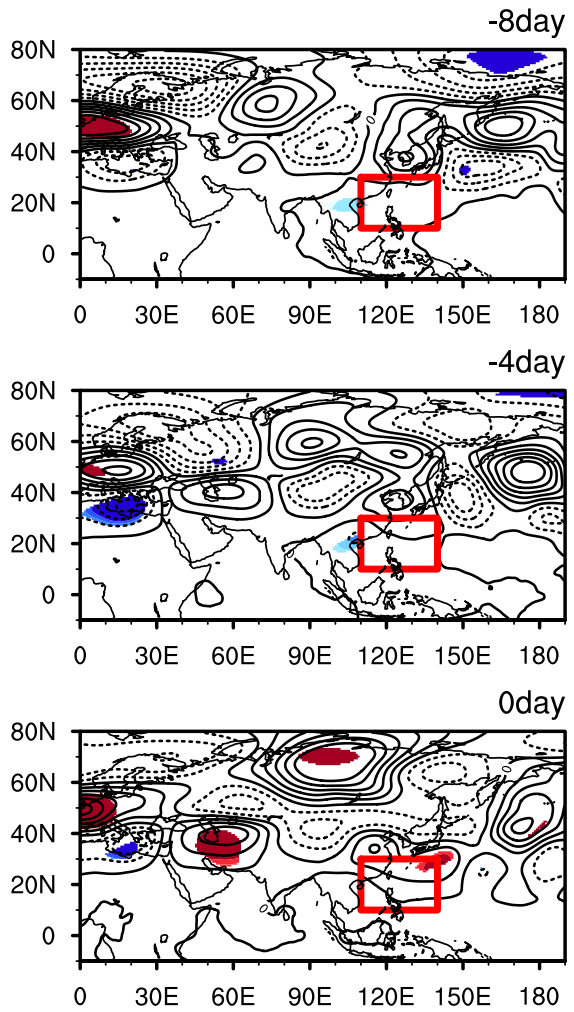

+4day

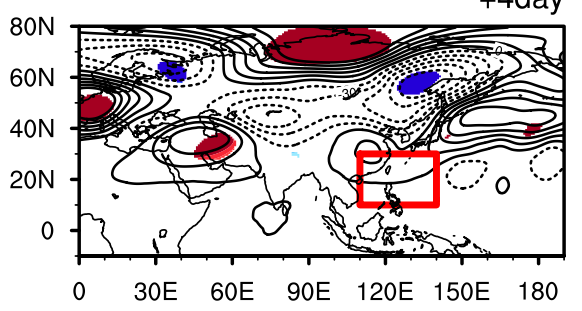

+8 day

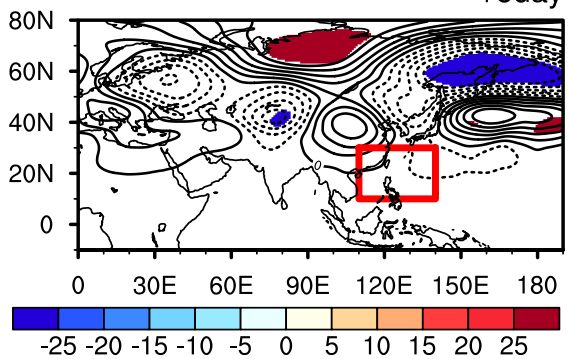

\subsection{Role of anomalous westward extension of the Sub-WPSH on SST changes}

The subseasonal atmospheric circulation may influence the SSTA by changing atmospheric radiation, the sea surface heat fluxes, and the upper ocean processes. Previous studies have demonstrated that the former plays a dominant role on subseasonal timescales (Wu 2010; Roxy and Tanimoto
2012). The westward extension of the WPSH has a crucial role in generating positive SSTA via above-normal incident solar radiation and below-normal surface latent heat release. Thus, we analyze the forcing of the Sub-WPSH on the local SSTA by examining radiation and heat fluxes at the air-sea interface. Figure 13 displays the Hovmoller plots of subseasonal anomalies of Z500, SST, the net solar radiation, OLR, latent heat flux at the air-sea interface, and 10-m wind speed 
Fig. 10 Lagged composites of the geopotential height anomaly at $500 \mathrm{hPa}$ (shades) for PC2 positive cases at a early summer, b late summer. The lags show a range from -8 to +8 days with an interval of 4 days. The shading areas are significant at $95 \%$ confidence level for $\mathrm{Z} 500$. The purple lines are $5880 \mathrm{~m}$ contour

\section{(a) Z500 in early summer}
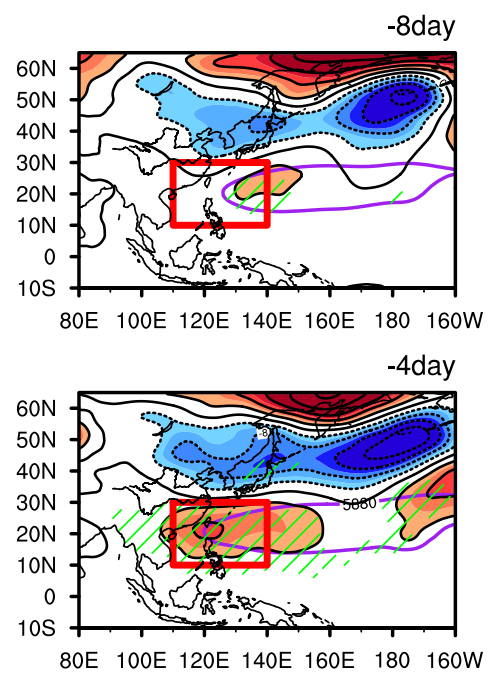

Oday

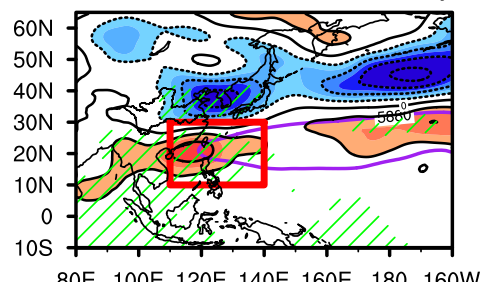

80E 100E 120E 140E 160E 180 160W
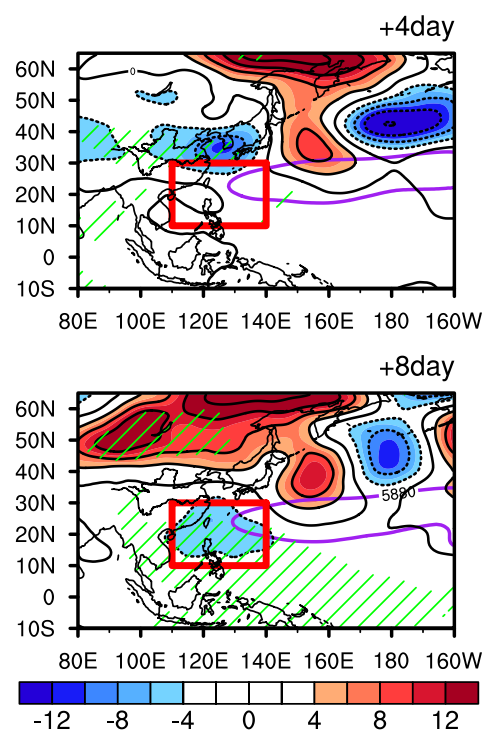

(b) Z500 in late summer
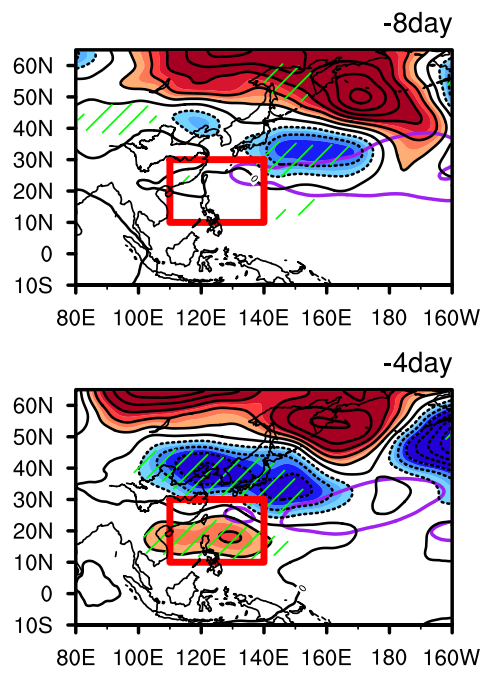

Oday
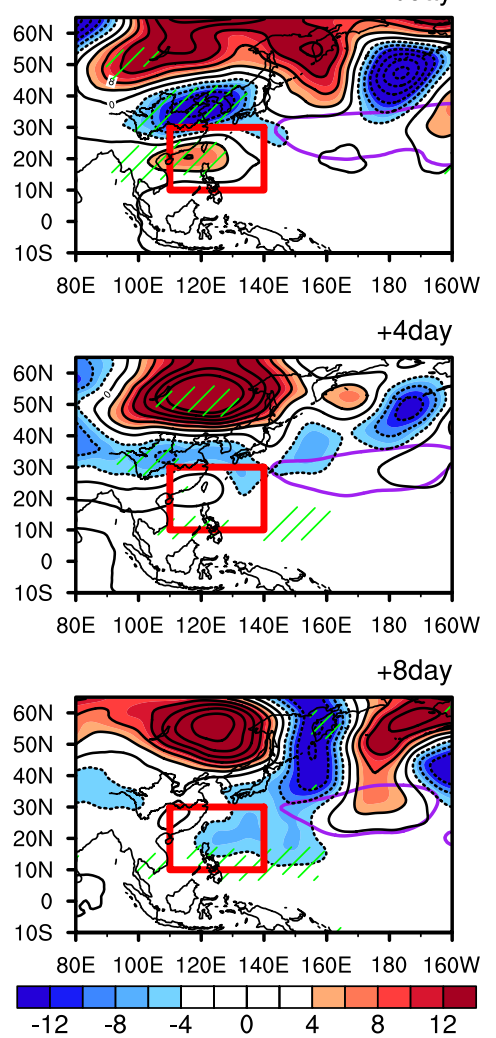

averaged over $10-30^{\circ} \mathrm{E}$ for positive Sub-WPSH cases in early and late summer. Positive anomalies of OLR and net solar radiation are associated with suppressed convection during the westward extension of the WPSH (Fig. 13c). Meanwhile, the decreased 10-m wind speed is responsible for the positive latent heat flux anomalies (Fig. 13e). Therefore, both solar radiation and surface latent heat anomalies favor the warming of local SST, leading to positive SSTAs (Fig. 13a). Anomalous anticyclones both in early and late summer can produce warm SST through the above mentioned processes. In late summer, stronger forcing of SST on the atmosphere is found possibly due to the colder local SSTA before the westward stretch of positive Sub-WPSH variability, which leads to stronger anticyclonic anomalies and thus more incident solar radiation to the ocean (Fig. 13d). The positive OLR is stronger in late summer than early summer, suggesting suppressed convective activity during late summer (Fig. 13d). The negative latent heat flux resulting from the 
Fig. 11 Lagged composites of SST anomaly (shades) for early summer (a) and late summer (b). The shading areas are significant at $95 \%$ confidence level for SST (a) SST in early summer
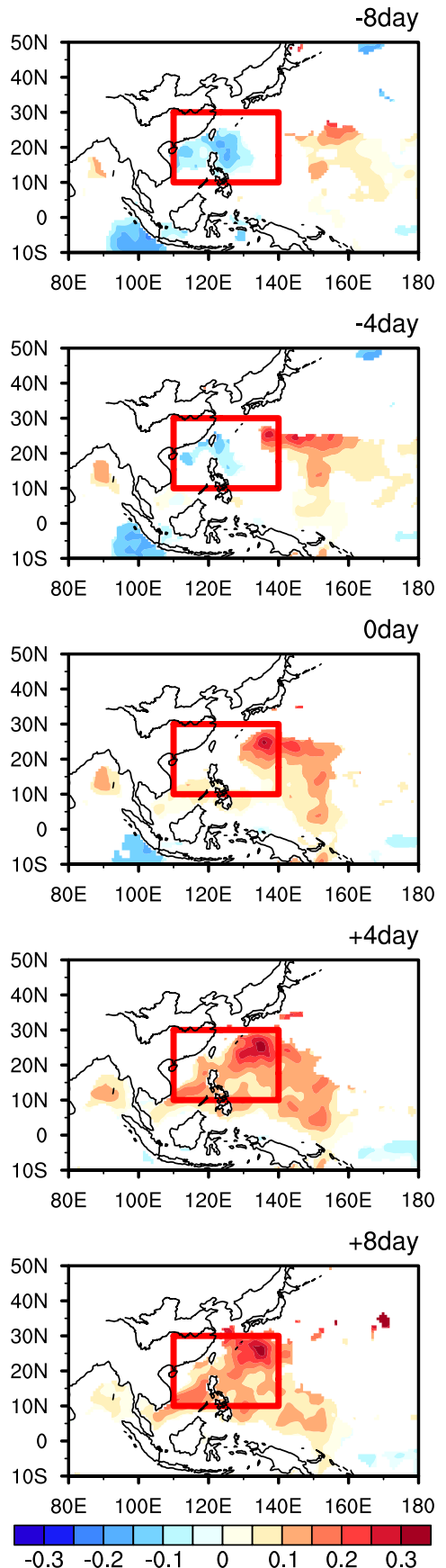

(b) SST in late summer

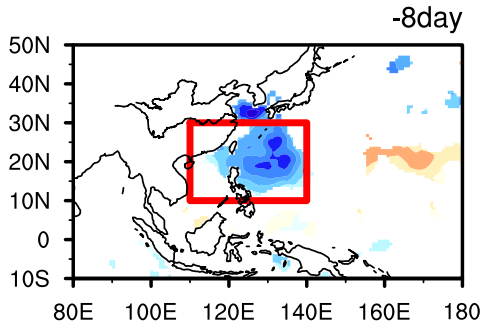

$-4 d a y$

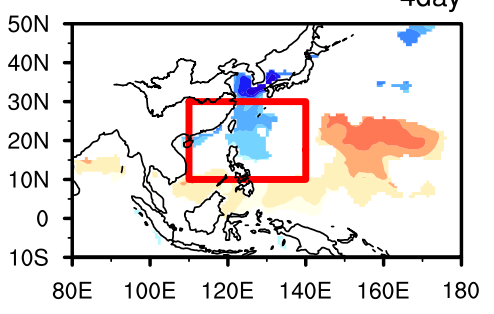

day
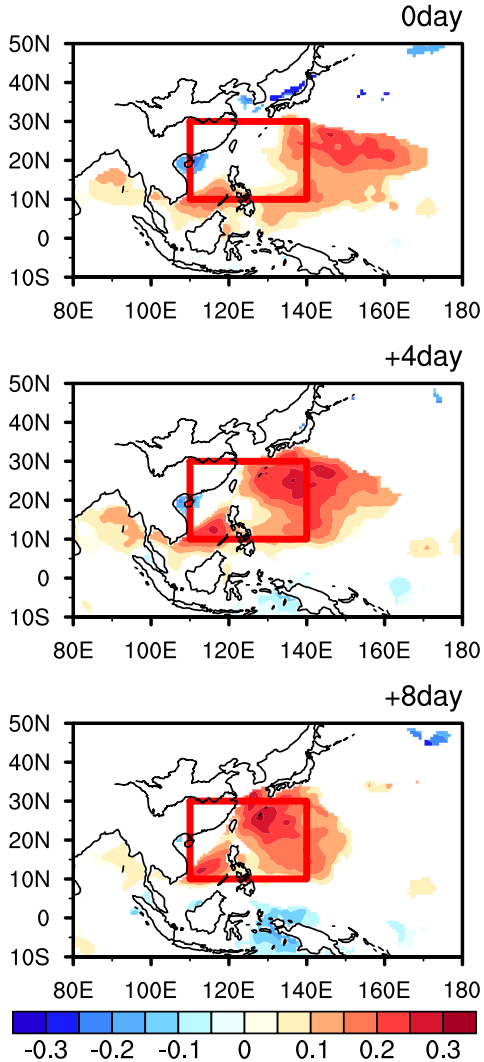

decreased lower-level wind speed suggests that the ocean releases less latent heat to the atmosphere (Fig. 13f). Thus, the anomalous anticyclone in late summer is stronger than that in early summer, consistent with the stronger SSTA in late summer (Fig. 13b).

Figure $14 \mathrm{a}$, b show the composites of the net solar radiation anomalies, OLR, latent and sensible heat fluxes at the air-sea interface, $10-\mathrm{m}$ wind speed averaged over $10-30^{\circ} \mathrm{E}$, $110-140^{\circ} \mathrm{N}$ for positive Sub-WPSH cases in early and late summer. The OLR and net solar radiation anomalies increase gradually to above-normal values, accompanied by positive geopotential height anomalies at $500 \mathrm{hPa}$ from day -8 to 0 . The positive OLR and net solar radiation anomalies indicate suppressed convective activity and more solar insolation. Meanwhile, the latent and sensible heat fluxes switch from positive to negative as a result of the decreased 10-m wind speed. Therefore, the ocean releases less latent heat to the atmosphere. The solar radiation and latent heat anomalies then result in the warming of local SST. Accompanied by the decrease of geopotential height anomalies at 


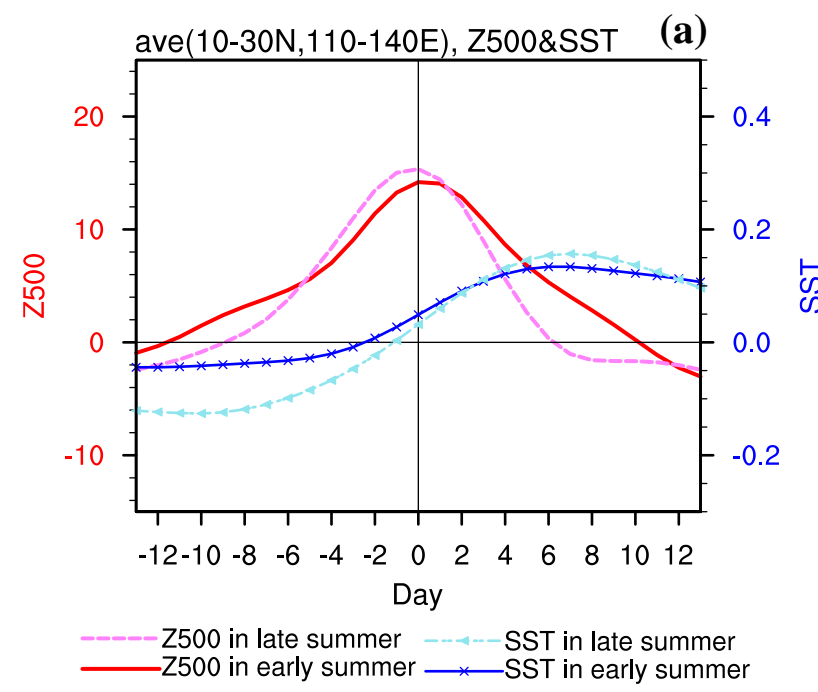

$500 \mathrm{hPa}$ after day 0 , the solar radiation becomes weaker and the latent heat release increases. Thus, the positive SSTA becomes indistinct. Anomalous anticyclones both in early and late summer can produce warm SST through the above mentioned processes. However, the anomalous anticyclone in late summer is stronger than that in early summer, which leads to warmer SSTA in late summer.

\subsection{Distinct effects of SST anomaly on the early and later stages of Sub-WPSH}

Many other previous studies (Ren et al. 2013; Qian and Shi 2017) have demonstrated the existence of the SST forcing on the atmosphere over the Northwestern Pacific during summer, emphasizing the weakening effect of local warm SSTA on the WPSH. However, in the early stage of the Sub-WPSH, distinct differences in local negative SSTAs exist between early and late summer. Then, what is the effect of the cold SSTAs on the subseasonal air-sea interaction? Fig. 12c displays the composites of $\Delta \theta_{\mathrm{e}}$ averaged over $10-30^{\circ} \mathrm{E}, 110-140^{\circ} \mathrm{N}$ for positive Sub-WPSH cases in early and late summer. Before day 0 , colder SST with increased SST gradient (figure not shown) in late summer leads to a convectively stable condition in the lower atmosphere, which favors generation of anomalous anticyclonic circulation in the mid-to-lower levels during the westward extension of the WPSH. After day 0, local positive SSTAs lead to convectively unstable condition both in early and late summer, diminishing the preexisting anomalous anticyclonic circulation in the mid-lower levels (Wu 2010; Roxy and Tanimoto 2012; Wang et al. 2012). The positive SSTAs then weaken the anomalous anticyclone, and lead to the eastward retreat of the WPSH and a faster weakening of the local anomalous anticyclone. Thus, the forcing of local SSTA on the SubWPSH changes from a positive one to a negative one.

\section{Summary and discussion}

This study investigated characteristics and mechanisms of the zonal displacement of the WPSH on subseasonal time scales, by using daily reanalysis data from 1979 to 2015 . A Sub-WPSH index, with a dominant period of 10-40 days, was defined by subseasonal anomalies of Z500 averaged over the core region $\left(10-30^{\circ} \mathrm{N}, 110-140^{\circ} \mathrm{E}\right)$, which can well depict the zonal variations of the WPSH over its western edge. Based on the index, 51 (59) positive (negative) events were identified for the summers of 1979-2015. Main characteristics of the subseasonal zonal variability of the WPSH were presented by lagged composites of the 5880 -line at $500 \mathrm{hPa}$ and the 1490 -line at $850 \mathrm{hPa}$ for 51 positive events. When the Sub-WPSH is at its westernmost position (denoted as day 0), positive Z500 anomalies and 
Fig. 13 Hovmoller plots of composite subseasonal anomalies of SST (shaded), Z500 (contours), OLR (shaded), net solar radiation (contours), latent heat fluxes (shaded), 10-m wind speed (contours) for early (a, c, e) and late $(\mathbf{b}, \mathbf{d}, \mathbf{f})$ summers, respectively (a) Early summer, Z500\&SST, ave(10-30N)

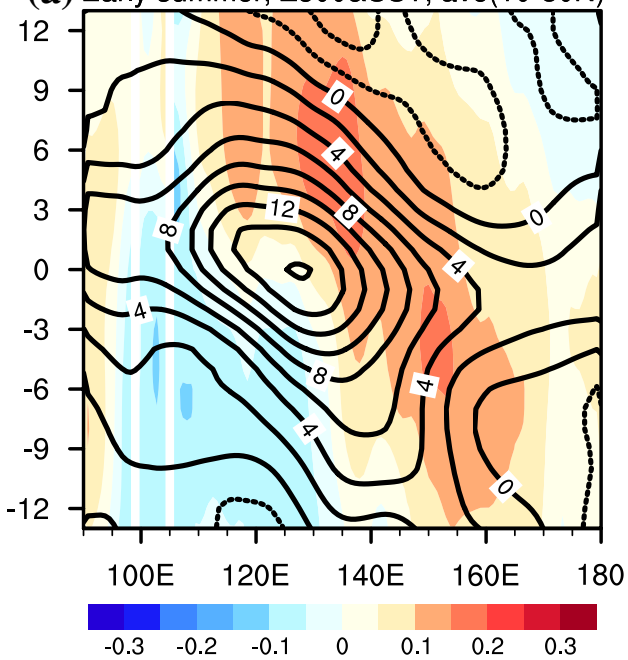

(c) Early summer, Solar\&OLR, ave(10-30N)

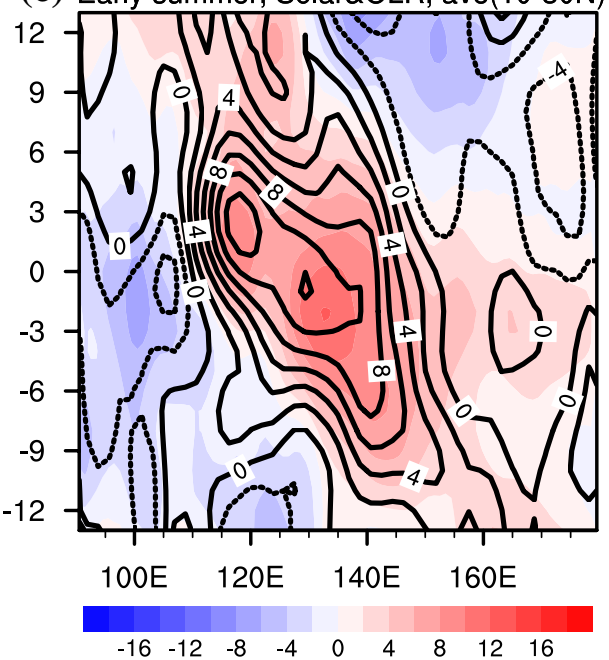

(e) Early summer, LH\&U10, ave(10-30N)

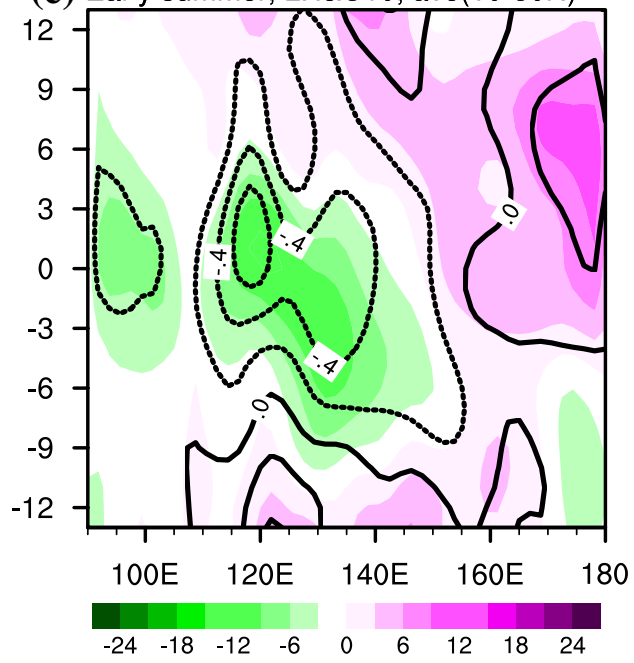

(b) Late summer, Z500\&SST, ave(10-30N)

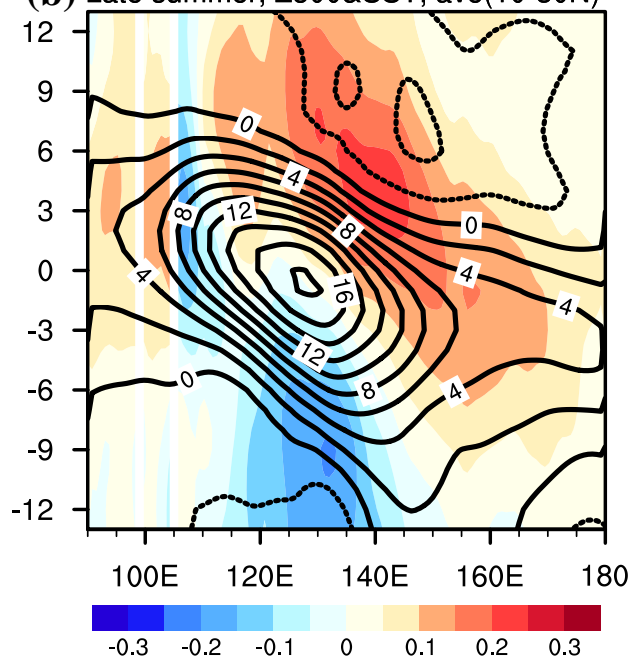

(d) Late summer, Solar\&OLR, ave $(10-30 \mathrm{~N})$

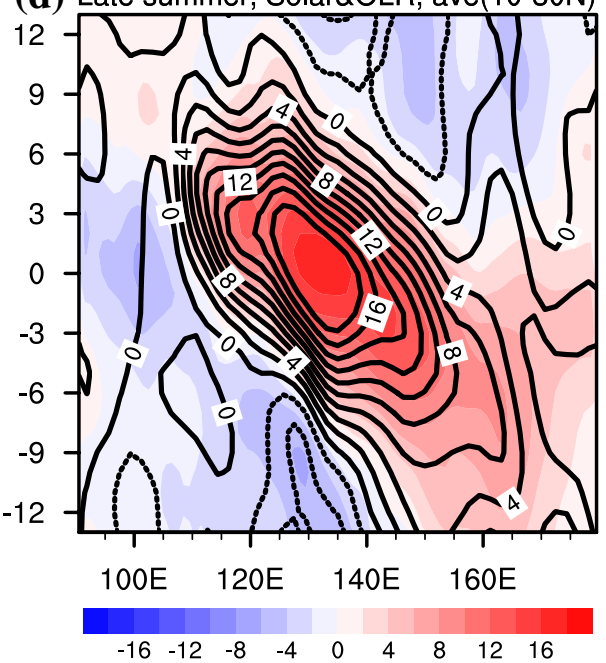

(f) Late summer, LH\&U10, ave(10-30N)

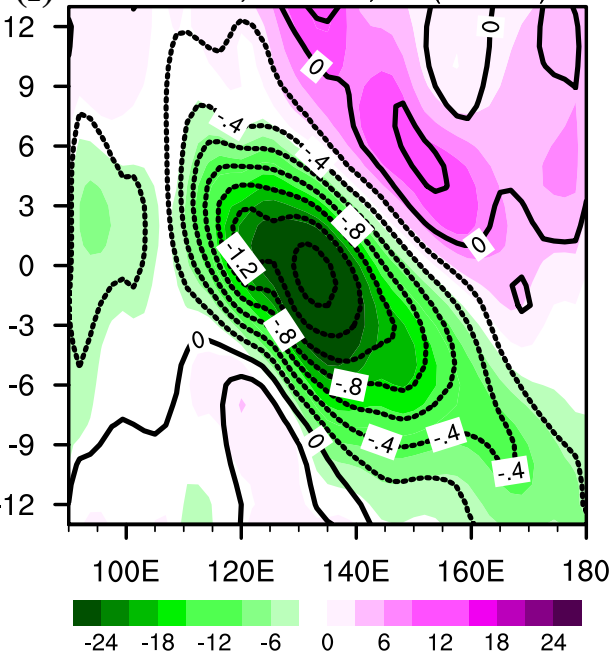


Fig. 14 Composite subseasonal anomalies of SST, Z500, OLR, net solar radiation, latent and sensible heat fluxes, $10-\mathrm{m}$ wind speed for early (a) and late (b) summers, respectively (a) $\operatorname{ave}(10-30 \mathrm{~N}, 110-140 \mathrm{E})$

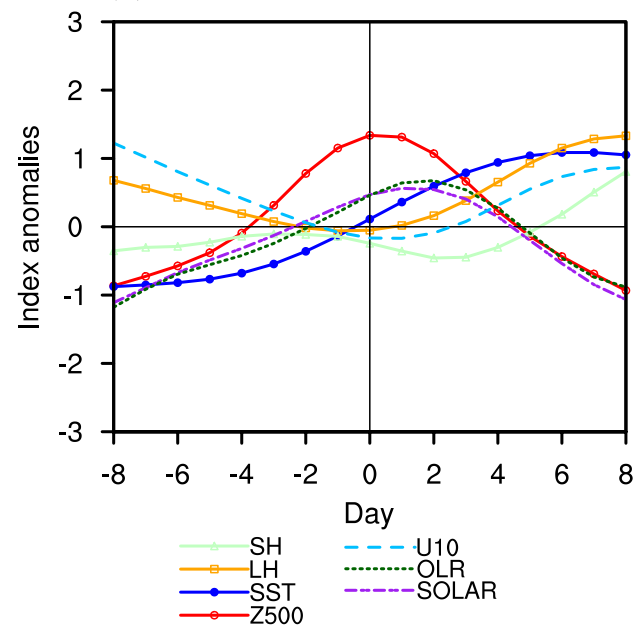

(b) ave $(10-30 \mathrm{~N}, 110-140 \mathrm{E})$

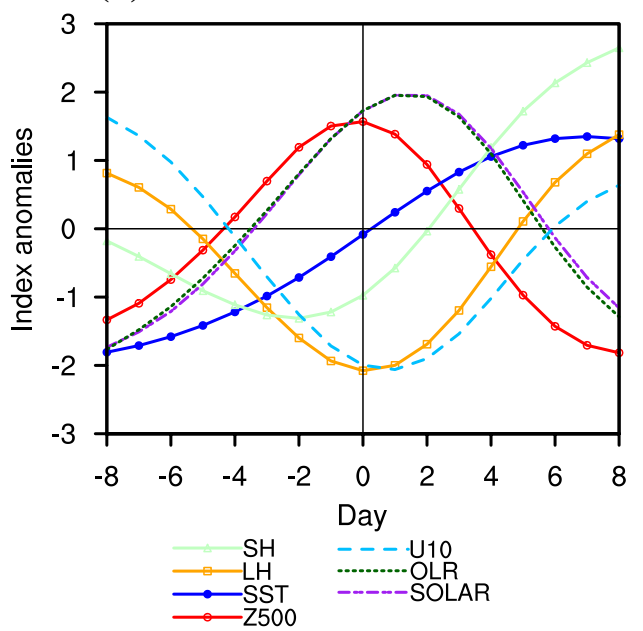

an anomalous anticyclone at $850 \mathrm{hPa}$ are sustained over the core region. Meanwhile, positive SSTAs are evident beneath the western edge of the Sub-WPSH. Above-normal rainfall over the Yangtze-Huaihe river basin and below-normal precipitation over the south of the Yangtze River are maintained for at least 1 week accompanied by the subseasonal westward extension of the Sub-WPSH. During negative events, the Sub-WPSH is located more eastward with opposite local SSTA and persistent precipitation anomalies compared with the positive events.

Figure 15 depicts the effect of wave trains and air-sea interaction on the WPSH. Considering the influences of mid-latitude atmospheric wave trains on the Sub-WPSH, the zonal variability of the Sub-WPSH in early summer is shown to be associated with two wave trains: the EAP wave train pattern in the middle troposphere and the SRP wave train in the upper troposphere. In early summer, an upperlevel anomalous anticyclone over the core region, responsible for the subseasonal westward extension of the WPSH, tends to be associated with propagation of both the EAP and SRP wave trains. Low latitude and mid-latitude signals have common influences on the WPSH during early summer. The propagation of the mid-latitude wave train (SRP) may cause the eastward extension of the South Asia high and divergence in upper troposphere. Thus, ascending motion over the Yangtze-Huaihe basin and descending motion over the subtropical western Pacific are established accompanied by the westward extension of the WPSH, and the anomalous heating over the Yangtze-Huaihe basin is further conducive to the WPSH's westward extension (Guan et al. 2018). In
Fig. 15 Schematics for the effect of air-sea interaction and wave trains on the WPSH

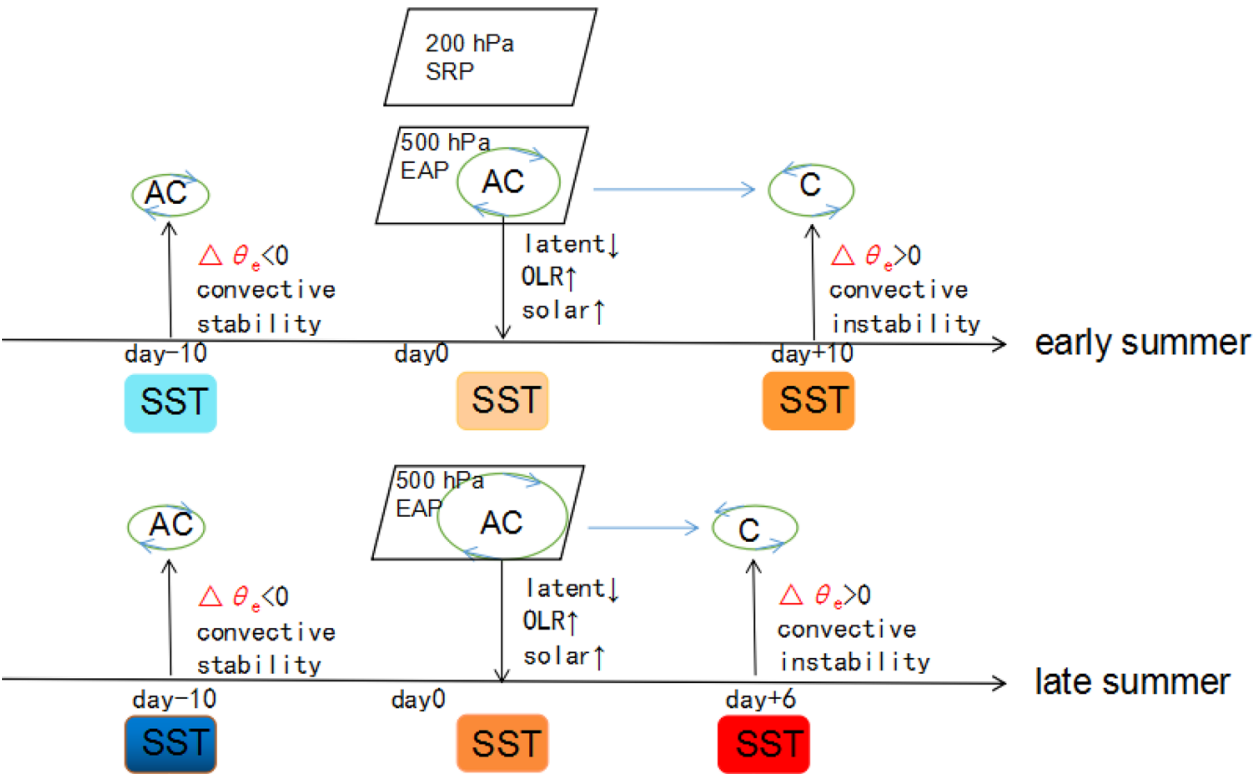


contrast, the zonal shift of the Sub-WPSH in late summer is merely affected by the EAP wave train, and the EPA wave train is clearly stronger at this time.

Subseasonal air-sea interaction also has a role on the zonal displacement of the Sub-WPSH. There are two distinct phases during evolution of the Sub-WPSH: first westward extension and then eastward retreat. The local SSTAs have different effects during the two stages of the Sub-WPSH zonal shift. At the early stage of the Sub-WPSH stretching westward, negative SSTAs cover the East Asian coastal water south of $30^{\circ} \mathrm{N}$. This forms a favorable condition for intensification of the local anomalous anticyclone. Then, the anticyclonic anomalies lead to increase of local SSTAs by changing radiation and heat fluxes at the air-sea interface. During the eastward retreat stage, positive SSTAs persist for several days, which promotes the transition of low-level circulation from anticyclonic to cyclonic anomalies. After that, the positive SSTAs gradually decrease. Due to the stronger negative local SSTAs during the first stage of Sub-WPSH in late summer, stronger anticyclonic anomalies are observed which induce stronger solar radiation into the ocean. As a result, the local warmer SSTAs during the second stage of the Sub-WPSH quickly weaken the anticyclonic anomalies with a shorter maintenance cycle than that in early summer. Therefore, the local air-sea interaction is another cause of the zonal variability of the Sub-WPSH.

While the relationship between two wave trains and zonal variability of the Sub-WPSH have been addressed in this study, the detailed mechanisms for the EAP and SRP wave trains require further study. Moreover, this paper only provides observational studies focusing on the effect of subseasonal air-sea interaction on the WPSH; numerical simulations are required in the future study to confirm the several processes identified in this study. Experiments based on atmosphere-ocean coupled and atmospheric-only models will be useful to to investigate different roles of the air-sea interaction for the subseasonal WPSH variations during early and late summers.

Acknowledgements All the authors share the first author. This work has benefited from discussions with Prof. William Perrie of BIO. The authors thank the anonymous reviewers for their valuable comments and suggestions, and Dr. Astrid at University of Bergen for helpful revision. Thanks to the support of the Jiangsu provincial Innovation Center for climate change. This work was supported by National Key R\&D Program of China (Grant nos. 2018YFC1505903 and 2016YFA0600303), the National Natural Science Foundation of China (Grant nos. 41621005 and 41330420 and 41675064 and 41675067 and 41875086), the Jiangsu Province Science Foundation (Grant no. SBK2015020577). This work was jointly supported by the Jiangsu Collaborative Innovation Center of Climate Change and Key Laboratory Project Foundation (Grant no. KLME1501). The NCEP/NCAR reanalysis data used in this study was obtained from https://www.esrl. noaa.gov/psd/data/gridded/data.ncep.reanalysis.html. The ERA-Interim reanalysis data used in this study was obtained from http://apps.ecmwf .int/datasets/data/interim-full-daily/levtype $=\mathrm{pl} /$. The NOAA OLR data used in this study was obtained from https://www.ncei.noaa.gov/data/ outgoing-longwave-radiation-daily/access/. The APHRODITE rain data used in this study was obtained from http://www.chikyu.ac.jp/ precip/.

Open Access This article is distributed under the terms of the Creative Commons Attribution 4.0 International License (http://creativeco mmons.org/licenses/by/4.0/), which permits unrestricted use, distribution, and reproduction in any medium, provided you give appropriate credit to the original author(s) and the source, provide a link to the Creative Commons license, and indicate if changes were made.

\section{References}

Bueh C, Shi N, Ji L, Wei L, Tao S (2008) Features of the EAP events on the medium-range evolution process and the mid- and highlatitude Rossby wave activities during the Meiyu period. Chin Sci Bull 53:610-623

Chang C-P et al (2000a) Interannual and interdecadal variations of the East Asian summer monsoon and tropical Pacific SSTs. Part I: roles of the subtropical ridge. J Clim 13:4310-4325

Chen Y, Zhai PM (2015) Synoptic-scale precursors of the East/Asia Pacific teleconnection pattern responsible foe persistent extreme precipitation in the Yangtze River Valley. Q J R Meteorol Soc 141:1389-1403

Chen X, Zhou T (2014) Relative role of tropical SST forcing in the 1990s periodicity change of the Pacific-Japan pattern interannual variability. J Geophys Res Atmos. https://doi.org/10.1002/2014J D022064

Chen X et al (2017) Relative contributions of external SST forcing and internal atmospheric variability to July-August heat wave over the Yangtze River valley during 1979-2014. Clim Dyn. https://doi. org/10.1007/s00382-017-3871-y

Dee DP et al (2011) The ERA-Interim reanalysis: configuration and performance of the data assimilation system. Q J R Meteorol Soc 137:553-597. https://doi.org/10.1002/qj.828

Ding Y, Chan JC (2005) The East Asian summer monsoons: an overview. Meteorol Atmos Phys 89:117-142

Ding QH, Wang B (2007) Intraseasonal teleconnection between the Summer Eurasian wave train and the Indian monsoon. J Clim 20:3751-3767

Enomoto T, Hoskins B, Matsuda Y (2003) The formation mechanism of the Bonin high in August. Q J R Meteorol Soc 129:157-178

Guan WN, Ren XJ, Shang W et al (2018) Subseasonal zonal oscillation of the western Pacific subtropical high during early summer. J Meteorol Res 32(5):768-780. https://doi.org/10.1007/s1335 1-018-8061-2

Hedon H, Glick J (1997) Intraseasonal aie-sea interaction in the tropical Indian and Pacific oceans. J Clim 10:647-661

Hirota N, Takahashi M (2012) A tripolar pattern as an internal mode of the East Asian summer monsoon. Clim Dyn 39:2219-2238

Hsu H, Lin S (2007) Asymmetry of the tripole rainfall pattern during the East Asian summer. J Clim 20:4443-4458

Huang SS (1963) Longitudinal movement of the subtropical anticyclone and its prediction (in Chinese). Acta Meteorol Sin $33: 320-332$

Huang R (1990) Studies on the teleconnections of the general circulation anomalies of East Asia causing the summer drought and flood in China and their physical mechanism (in Chinese), Chin. J Atmos Sci 14:108-117

Huang G (2004) An index measuring the interannual variation of the East Asian summer monsoon. Adv Atmos Sci 21:41-52 
Huang R, Li W (1987) Influence of the anomaly of heat source over the northwestern tropical Pacific for the subtropical high over East Asia. In: Proceedings international conference on the general circulation of East Asia, Chengdu, China, 10-15 Apr 1987, pp 40-45

Huang R, Sun F (1992) Impacts of the tropical western Pacific on the East Asia summer monsoon. J Meteorol Soc Jpn 70:243-256

Huffman GJ, Adler RF, Morrissey MM, Crutis S, Joyce R, McGavock B, Susskind J (2001) Global precipitation at one-degree daily resolution from multi-satellite observation. J Hydrometeorol 2:36-50

Kalnay E et al (1996) The NCEP/NCAR 40-year reanalysis project. Bull Am Meteorol Soc 77:437-471

Kawatani Y, Ninomiya K, Tokioka T (2008) The North Pacific subtropical high characterized separately for June, July, and August: zonal displacement associated with submonthly variability. J Meteorol Soc Jpn 86:505-530

Kosaka Y, Nakamura H (2006) Structure and dynamics of the summertime Pacific-Japan teleconnection pattern. Q J R Meteorol Soc 132:2009-2030

Krishnamurthy V, Shukla J (2000) Intraseasonal and interannual variability of rainfall over India. J Clim 13:4366-4377

Lau KM, Weng H (2002) Recurrent teleconnection patterns linking summertime precipitation precipitation variability over East Asia and North America. J Meteorol Soc Jpn Ser II 80:1309-1324

Lee SS, Seo YW, Ha KJ, Jhun JG (2013) Impact of the western North Pacific subtropical high on the East Asian monsoon precipitation and the Indian Ocean precipitation in the boreal summertime. Asia Pac J Atmos Sci 49(2):171-182

Li RC, Zhou W, Li T (2014) Influences of the Pacific-Japan teleconnection pattern on synoptic-scale variability in the western North Pacific. J Clim 27:140-154

Li T et al (2017) Theories on formation of an anomalous anticyclone in western North Pacific during El Niño: a review. J Meteorol Res 31(6):987-1006. https://doi.org/10.1007/s13351-017-7147-6

Liebmann B, Smith CA (1996) Description of a complete (interpolated) outgoing longwave radiation dataset. Bull Am Meteorol Soc 77:1275-1277

Liu H, Zhang DL, Wang B (2008) Daily to submonthly weather and climate characteristics of the summer 1998 extreme rainfall over the Yangtze River basin. J Geophys Res 113:D22101

Lu R (2001) Interannual variability of the summertime North Pacific subtropical high and its relation to atmospheric convection over the warm pool. J Meteorol Soc Jpn 79:771-783

Lu R, Dong B (2001) Westward extension of North Pacific subtropical high in summer. J Meteorol Soc Jpn 79:1229-1241

Lu R, Oh JH, Kim BJ (2002) A teleconnection pattern in upper-level meridional wind over the North African and Eurasian continent in summer. Tellus 54A:44-55

Mao J, Xu G (2006) Intraseasonal variations of the Yangtze rainfall and its related atmospheric circulation feature during the 1991 summer. Clim Dyn 27:815-830

Mao J, Sun Z, Wu G (2010) 20-50-Day oscillation of summer Yangtze rainfall in response to intraseasonal variations in the subtropical high over the western North Pacific and South China Sea. Clim Dyn 34:747-761

Nitta T (1987) Convective activities in the tropical western Pacific and their impact on the Northern Hemisphere summer circulation. J Meteorol Soc Jpn 65:373-390

Qian W, Shi J (2017) Tripole precipitation pattern and SST variations linked with extreme zonal activities of the western Pacific subtropical high. Int J Climatol 37:3018-3035. https://doi. org/10.1002/joc.4897

Qian C et al (2014) Multidecadal variability of North China aridity and its relationship to PDO during 1900-2010. J Clim 27(3):1210-1222
Ren XJ, Yang XQ, Sun XG (2013) Zonal oscillation of western Pacific subtropical high and subseasonal SST variations during Yangtze persistent heavy rainfall events. J Clim 26:8929-8946

Ren XJ, Yang DJ, Yang XQ (2015) Characteristics and mechanisms of the subseasonal eastward extension of the South Asian High. J Clim 28:6799-6822. https://doi.org/10.1175/JCLI-D-14-00682.1

Roxy M, Tanimoto Y (2012) Influence of sea surface temperature on the intraseasonal variability of the South China Sea summer monsoon. Clim Dyn 39:1209-1218

Tao S, Chen L (1987) A review of recent research on the East Asian summer monsoon in China. In: Chang C-P, Krishnamurti TN (eds) Monsoon meteorology. Oxford University Press, Oxford, pp 60-92

Tao S, Wei J (2006) The westward, northward advance of the subtropical high over the West Pacific in summer (in Chinese). Chin J Appl Meteorol Sci 17:513-525

Tao S, Zhu F (1964) The 100-mb flow patterns in southern Asia in summer and its relation to the advance and retreat of the WestPacific subtropical anticyclone over the far east (in Chinese). Acta Meteorol Sin 34:385-396

Terao T (1998) Barotropic disturbances on intraseasonal time scales observed in the midlatitudes over the Eurasian Continent during the northern summer. J Meteorol Soc Jpn 76:419-436

Vecchi G, Harrison D (2002) Monsoon breaks and subseasonal sea surface temperature variability in the Bay of Bengal. J Clim 15:1485-1493

Wakabayashi S, Kawamura R (2004) Extraction of major teleconnection patterns possibly associated with the anomalous summer climate in Japan. J Meteorol Soc Jpn 82:1577-1588

Wang N, Zhang Y (2015) Connections between the Eurasian teleconnection and concurrent variation of upper-level jets over East Asia. Adv Atmos Sci 32:336-348

Wang WC, Gong W, Wei H (2000b) A regional model simulation of the 1991 sever precipitation event over the Yangtze-Huai River valley. Part I: precipitation and circulation statistics. J Clim 13:74-92

Wang L, Li T, Zhou T (2012) Intraseasonal SST variability and air-sea interaction over the Kuroshio Extension region during boreal summer. J Clim 25:1619-1634

Wu R (2010) Subseasonal variability during the South China Sea summer monsoon onset. Clim Dyn 34:629-642

Wu L, Wang C (2015) Has the western Pacific subtropical high extended westward since the late 1970s? J Clim 28:5406-5413. https://doi.org/10.1175/JCLI-D-14-00

Wu B, Zhou T (2016) Impacts of the Pacific-Japan and circumglobal teleconnection patterns on the interdecadal variability of the East Asian summer monsoon. J Clim 29:3253-3271

Wu B et al (2008a) Oceanic origin of the interannual and interdecadal variability of the summertime western Pacific subtropical high. Geophys Res Lett 35:L13701. https://doi.org/10.1029/2008G L03458

Wu R, Kirtman B, Pegion K (2008b) Local rainfall-SST relationship on subseasonal time scales in satellite observations and CFS. Geophys Res Lett 35:L22706

Wu J, Xu XF, Jin FF, Guo PW (2013) Research of the intraseasonal evolution of the East Asia Pacific pattern and the maintenance mechanism (in Chinese). Acta Meteorol Sin 71:476-491

Wu B, Lin J, Zhou T (2016) Interdecadal circumglobal teleconnection pattern during boreal summer. Atmos Sci Lett 17:446-452. https ://doi.org/10.1002/asl.677

Xie P, Yatagai A, Chen M, Hayasaka T, Fukushima Y, Liu C, Yang $S$ (2007) A gauge-based analysis of daily precipitation over East Asia. J Hydrometeorol 8:607-627

Yang J, Bao Q, Wang B, Gong D, He H, Gao M (2013) Distinct quasibiweekly features of the subtropical East Asian monsoon during early and late summers. Clim Dyn 42:1469-1486 
Yatagai A, Kamiguchi K, Arakawa O, Hamada A, Yasutomi N, Kitoh A (2012) APHRODITE: constructing a long-term daily gridded precipitation dataset for Asia based on a dense network of rain gauges. Bull Am Meteorol Soc 93:1401-1415

Zhou TJ, Yu RC (2005) Atmospheric water vapor transport associated with typical anomalous summer rainfall patterns in China. $\mathrm{J}$ Geophys Res Atmos 110:D08104. https://doi.org/10.1029/2004j d005413

Zhou TJ, Yu RC (2009) Why the western Pacific subtropical high has extended westward since the late 1970s. J Clim 22:2199-2215
Zhou TJ et al (2009) Detecting and understanding the multi-decadal variability of the East Asian Summer Monsoon? Recent progress and state of affairs. Meteorol Z 18(4):455-467

Publisher's Note Springer Nature remains neutral with regard to jurisdictional claims in published maps and institutional affiliations. 